1 Distribution and habitat of Australian Pied Oystercatchers Haematopus longirostris

2 along the SE Australian coast

3 Stephen Totterman

$4 \quad$ Empire Vale, NSW, 2478, Australia

\title{
5 SUMMARY
}

6 Australian Pied Oystercatchers Haematopus longirostris and their habitat were surveyed on

$7 \quad 72$ beaches and $674 \mathrm{~km}$ of the SE Australian Coast, from Fraser Island, Queensland to near

8 the New South Wales-Victoria state border and between 2015-2018. A grand total of 41

9 oystercatcher territories and 232 individual birds (the sum of mean beach counts) were

10 counted. Bird-habitat models for oystercatcher mean count density indicated a positive

11 response to the abundance of the primary prey species Donax deltoides, a large 'surf clam' and commonly known as the 'pipi', a negative response to the proportion of beach length urban and a negative S-N trend. Models for oystercatcher territory density indicated a positive response to pipi abundance and a negative response to pedestrian access density. This report upgrades the coastal development, tourism and human recreation disturbance threats for the species and calls for the long term protection of beach-nesting bird habitat.

Keywords: beach nesting bird; bird-habitat model; coastal development; Donax deltoides; human recreation disturbance; sandy ocean beach; species distribution model; surf clam

\section{INTRODUCTION}

The Australian Pied Oystercatcher Haematopus longirostris inhabits estuaries and ocean beaches around the Australian coast, with major populations in the southern states of Tasmania, South Australia and Victoria (reviewed in Taylor et al. 2014). The species is nonmigratory and many breeding pairs remain on their territories throughout the year. Like other oystercatcher species, the density of Australian Pied Oystercatcher breeding pairs is usually limited by territorial behaviour. The ecology of oystercatchers on ocean beaches is not well known.

Microtidal, high energy ocean beaches (surf beaches) are common along the SE Australian coast (Short 2007). These are narrow, essentially linear habitats with a narrow intertidal zone. Australian Pied Oystercatchers typically nest on the low fore dune (Wellman et al. 2000). Beach width and length spatial constraints and territorial behaviour mean that beach-resident oystercatcher populations are smaller than those counted in large estuaries (see Taylor et al. 2014) and are dispersed along the coast. Totterman (2019a) measured mean beach widths in the range 31-84 $\mathrm{m}$ (from the base of the fore dune to the middle of the low tide swash zone) for 11 beaches on the Far North Coast of the state of New South Wales (NSW). These beach widths are similar to reported flight (reviewed in Weston et al. 2012) or $129 \mathrm{~m}$ for a human and dog stimulus (Harrison 2009). 
39 People also disperse from beach access points in the along shore direction. Totterman (2019c)

40 reported that beach walking, commonly with dogs, is the most frequent beach recreation

41 activity on the Far North Coast of NSW and the $444 \mathrm{~m}$ mean distance walked along shore is

42 one order of magnitude greater than mean flight initiation distances for Australian Pied

43 Oystercatchers.

44 Commonly known as the 'pipi', Donax deltoides is a large 'surf clam' that inhabits the

45 intertidal and shallow subtidal zones on ocean beaches from Fraser Island, in the state of

46 Queensland, to the Murray River, South Australia (Ferguson et al. 2018). Pipis are the major

47 prey for Australian Pied Oystercatchers on ocean beaches in NSW (Owner \& Rohweder

48 1997, Harrison 2009, Totterman 2018). Owner \& Rohweder (2003) reported that

49 oystercatchers aggregated at beaches with high pipi biomass (high mean pipi count density

50 and large mean pipi length). Totterman (2018) also reported oystercatcher-pipi abundance

51 correlations, however those results refer to a dynamic period of recovery of pipi stocks on a

52 single beach.

53 Pipis are also exploited by humans for food and as bait for recreational fishing. Owner \&

54 Rohweder (2003) and Harrison (2009) raised concerns about the potential negative impacts of

55 commercial fishing on pipi stocks and oystercatcher populations. However, surf clams are

56 fast-growing and short-lived, and weak or zero pipi recruitment can also result in pipi stock

57 declines (Murray-Jones 1999). Management responses to the recent 2003-2009 'pipi crash'

58 (Totterman 2018) that were introduced for the NSW commercial fishery in 2012 are: an

59 annual Dec-Jun temporal closure; spatial closures for certain beaches and zones within

60 certain beaches; a daily trip limit of $40 \mathrm{~kg}$ per fisher and a minimum size limit of $45 \mathrm{~mm}$

61 (Gray 2016a; Ferguson et al. 2018). Only hand gathering of pipis is allowed in NSW. The

62 NSW commercial fishery is small, with 52 licenses in 2018 (not all of which were necessarily

63 active) and a FY 2015-16 catch of $176 \mathrm{t}$ (Ferguson et al. 2018). There is no commercial pipi

64 fishing in Queensland.

65 Surf clams burrow themselves into the sand and are also mobile, at times emerging and

66 'riding' the wash up and down the beach face (Ellers 1995). This mobility and varying beach

67 and surf conditions results in surf clam aggregations that vary across small and large spatial

68 and temporal scales including tidal migrations, seasonal and other rhythmic patterns (e.g.

69 Totterman 2019a). Patchy and variable pipi abundance could explain the rather long

70 territories for oystercatchers on ocean beaches. The historical maximum density for South

71 Ballina Beach, which formerly supported the largest beach resident oystercatcher population

72 in NSW, is 18 breeding pairs over $18.7 \mathrm{~km}$ of available habitat in 2000 (NSW Department of

73 Planning, Industry and Environment (DPIE), unpubl. data), which equals $1.04 \mathrm{~km} /$ pair,

74 although territory lengths are not uniform.

75 Surf clams feed on suspended organic matter in the swash zone by extending their siphons to

76 the sand-water interface. Oystercatchers can locate buried pipis by visual searching for pipi

77 siphons or by tactile searching, probing the sand with their bills (Totterman 2018).

78 Oystercatchers who have located a pipi have little time to make careful prey size assessments

79 and act before the next wave arrives. Accordingly, and unlike many studies for the Eurasian 
Oystercatcher Haematopus ostralegus, size selection has not been reported for oystercatchers taking surf clams (Owner 1997, Taylor and Taylor 2005, Totterman 2018). Totterman (2018) further suggested no prey size selection among different prey types and noted that small prey also have small biomass and can reasonably be ignored in studies where large clams are frequently taken. The asymptotic oystercatcher feeding rate estimate in Totterman (2018) was 0.26 pipis per min of active foraging time. Like many other shorebird functional responses reviewed in Goss-Custard et al. (2006), this asymptote was reached at a low prey density of c. 5 pipis $/ \mathrm{m}^{2}$.

The Australian Pied Oystercatcher is currently listed as Endangered in NSW (NSW DPIE 2019a). For the entire global population, conservation threats recognised by Taylor et al. (2014) were human recreation disturbance, habitat loss, predators, clam harvesting, kelp harvesting (which is not relevant for more northerly temperate and sub-tropical beaches, where beach-washed kelp is scarce) and global climate change. BirdLife Australia have stated that the greatest conservation threat to beach nesting birds is disturbance from people visiting the beach (Birdlife Australia 2018).

Johnson (2002) advocated for replication of studies ('metareplication') to have confidence in the generality of findings. This study was motivated by concerns that Owner \& Rohweder (2003) missed the coastal development and human recreation disturbance threats for oystercatchers on ocean beaches and overstated the importance of pipis. The objective was to sample a larger number of beaches and re-examine oystercatcher-habitat associations for the SE Australian coast.

\section{STUDY AREA AND METHODS}

\section{Sampling design}

For estimating species-habitat models it is essential to include in the sample sites where the species is more abundant (Albert et al. 2010). A simple random sample of beaches would have resulted in many zero oystercatcher counts and little information for modelling abundance. This study purposely selected beaches where pipis and oystercatchers were expected to be more abundant.

The sampling space for this study extends from the Fraser Island, Queensland S to the NSWVictoria border (Fig. 1). There are few and short beaches around the NSW-Victoria border. Based on the results of Owner (1997), 117 exposed beaches with a SE to E aspect and > 1.5 $\mathrm{km}$ long, where pipis could be relatively abundant, were identified for the sampling frame. Beaches were defined by natural breaks (e.g. headlands and rivers). Some short beaches were combined if the break did not present a substantial barrier, e.g. a short, low rocky interval that could easily be traversed at all tides. Together with the results of Harrison (2009), sampling prioritised longer, less-developed beaches, where oystercatchers could be relatively abundant. Identification of high pipi abundance and high oystercatcher abundance beaches was also guided by information from other studies and reports (Gray 2016a,b, Totterman 2019b, NSW DPIE 2019b). 
The oystercatcher breeding season on the Far North Coast of NSW is Aug-Dec and late attempts generally are replacement clutches (Wellman et al. 2000). Sampling occurred early in the breeding season (Jul-Oct) when competition for territories and territory occupancy was assumed to be maximum. Sampling started with beaches in the $\mathrm{N}$ of the sampling space, progressed down the coast and usually included some more beaches on the return trip $\mathrm{N}$. Sampling in any one season selected non-adjacent beaches to reduce spatial autocorrelation that could result from short-distance movements of birds.

\section{Counts}

Beaches were surveyed with a handheld Global Positioning System (GPS) satellite receiver, marking 4-13 (mode 7) regularly spaced along shore waypoints at the high tide drift line to measure beach length and along shore distances for pipi sampling locations and oystercatcher territory mapping.

Oystercatchers were usually counted at low tide. A four-wheel-drive (4WD) vehicle was used on longer beaches, where permitted. Otherwise, and for shorter beaches, a bicycle was used. Some of the shortest beaches, and those with a steep face and soft sand, were walked.

Oystercatchers present in any estuaries, lakes or on sand spits adjacent to a beach were noted but not added to the beach count. Coastal lakes are common along the NSW South Coast, many of these are inhabited by oystercatchers and these birds can be found roosting and sometimes nesting adjacent to the beach. However, these birds forage and spend most of the time in the estuary or lake and are rarely seen on the intertidal zone of the beach. This study strictly counted oystercatchers on beaches and 'beach residents'.

'Adult'-plumage oystercatchers were counted including second immature plumage attained at $c$. one year old, which looks the same without close inspection. One and two year old oystercatchers have relatively dull colours of bill, legs and iris compared to adults (Marchant and Higgins 1993), but not all individuals could be inspected closely (e.g. birds at distance, in unfavourable light or flying past). Birds marked with bands or alphanumeric leg flags were noted to assist in the identification of local residents.

Territory mapping (spot mapping) was applied and each beach was counted a minimum of three times on non-consecutive days. Beaches with higher oystercatcher densities (birds $/ \mathrm{km}$ ) also tend to have higher territory densities and warrant extra counts. Territory mapping effort was increased to a minimum of five counts for beaches with $>0.5 \mathrm{birds} / \mathrm{km}$, based on breeding season densities for oystercatcher breeding beaches on the Far North Coast of NSW of 0.3-1.9 adults/km in Owner \& Rohweder (2003) and 0.5-1.9 adults/km in Harrison (2009). Supplementary counts were also made opportunistically for some beaches where pipi sampling continued beyond the oystercatcher counting period. Three to five counts was considered sufficient for a low-cost estimate of territories because oystercatchers on the beach are conspicuous and easy to find, territories are one-dimensional and the observer was experienced with spot-mapping oystercatcher territories on beaches (Totterman 2018). 
157 Oystercatcher territories were identified as adult 'pairs' that were present on the same stretch

158 of beach on at least two of three or three of five counts. These territory estimates are short-

159 term results using standardised methods and not all pairs that occupy a stretch of beach may

160 go on to breed. Counts of breeding pairs are costly, requiring frequent visits throughout the

161 breeding season. Territories are compared with independent counts of breeding pairs in the

162 Results.

\section{Pipi abundance}

164 A new 'feet digging' method (Totterman 2019b) was used to efficiently sample pipis and 165 enable precise beach-scale estimates of pipi abundance and mean pipi length. The method 166 was developed from a recreational fishing technique that involves twisting one's feet into the

167 thixotropic sand to dislodge buried clams which are then recovered by hand. Several plots are 168 sampled across the swash zone in one five-min sampling unit and the process is replicated at 169 several locations along the beach. Totterman (2019b) reported that mean feet digging pipi 170 counts were proportional to mean transect linear pipi densities $(r=0.98)$ and that pipi length171 frequency distributions from feet digging agreed with those from quadrat sampling except 172 that feet digging was not effective for pipis $<16 \mathrm{~mm}$. New pipi recruits are not always 173 present and can be ignored because biomass increases exponentially with shell length 174 (Murray-Jones 1999) and larger clams contribute more to oystercatcher diets (Totterman 175 2018).

176 Variance increases strongly with the mean pipi count (Totterman 2019b). A constant 177 precision stopping rule was applied for pipi sampling: stop sampling when $\mathrm{SE} \leq 2 \mathrm{pipis} / 5$ $178 \mathrm{~min}$. This stopping rule efficiently allocates effort to prevent oversampling of low pipi abundance beaches and undersampling of high abundance beaches. A first pass sampled pipis at 20 along shore locations, regularly spaced along a beach from a random starting distance and cycling through the tidal stages high, ebb, low and flow (i.e. with five locations sampled for each tide stage). If $\mathrm{SE}>2$ pipis $/ 5 \mathrm{~min}$, then further sampling passes, consisting of multiples of 20 along shore locations, were performed until the SE stopping rule was satisfied or a maximum sample size of 100 was reached. For three long, high pipi abundance beaches (Teewah, Bennetts and Stockton), the beach could be divided into low and high pipi abundance strata based on the first pass(es) and informal observations. Stratified sampling was then applied to more efficiently approach the SE stopping rule.

Pipi lengths were measured with a calliper to the nearest mm (maximum shell length). All only one pass and 20 locations were sampled then mean pipi length was based on $<100$ measurements. Otherwise, and if $<100$ pipis were sampled in the first pass, pipis were also measured for each subsequent pass until at least 100 pipis were measured. After that, pipis were only counted because measuring large numbers of pipis is time consuming and a sample size of 100 gives a precise mean pipi length. 
195

196

197

198

199

200

201

202

203

204

205

206

207

208

209

210

211

212

213

214

215

216

217

218

219

220

221

222

224

225

226

227

228

229

230

231

232

233

\section{Human recreation and other habitat variables}

Counts of people, dogs, 4WDs, motorcycles, bicycles, horses and, on Fraser Island, aircraft directly measure human recreation activity and were counted simultaneous with oystercatcher counts. Dogs included dingos (naturalised dogs) that were present in low densities on Fraser Island and in the Myall Lakes region, NSW. Counts of humans and dogs excluded those in $4 \mathrm{WDs}$ and in the surf. Motorcycle, bicycle, horse and aircraft counts were small, with grand totals of 3, 32, 42 and 4 respectively, and are not considered further.

Coastal development variables and indirect measures of human recreation that were recorded were: urban length, length of public beach driving zones, whether or not beach driving permits were required, length of dog exercise zones, length of beach adjoining any terrestrial protected areas (National Parks and Nature Reserves), counts of pedestrian and (where 4WDs were permitted) 4WD beach access tracks and counts of beach front and near beach camping grounds and caravan parks. Access tracks include public and private, formal and informal tracks. Tracks had to be frequently used and lead somewhere to be counted (e.g. temporary dune driving tracks were not counted). 4WD tracks were also used by pedestrians on many beaches but were not added to that count. Permits are not applicable for the majority of beaches sampled (i.e. where driving is not permitted) and this variable is not considered further.

Human population density was obtained from the $1 \times 1 \mathrm{~km}$ resolution Australian Population Grid 2011 (Australian Bureau of Statistics 2011). The intersection of a line defined by GPS survey waypoints with the Australian Population Grid 2011 identifies beach front grid cells and the sum of these cells equals the beach front human population.

Beach morphodynamic state (Short 2007) was observed during average surf conditions (i.e. not during erosive periods associated with storms and large swells) and one handful of intertidal sand was sampled at each GPS waypoint. Sand grain size was classified on the Wentworth scale by visual comparison to graded samples on a sand gauge. Any shell fragments present were ignored. Beach morphodynamic state and sand grain size within beaches were summarised as modal values.

\section{Statistical analysis}

Counts, zone lengths and human population are 'extensive variables' and scale with beach length. Extensive variables were converted to linear densities (e.g. birds $/ \mathrm{km}$ ) and proportions (e.g. urban proportion) by dividing by beach lengths (Owner \& Rohweder 2003). 'Intensive variables', e.g. mean pipi abundance and mean pipi length, do not scale with beach length.

There were two response variables in the dataset: oystercatcher mean total count/density and oystercatcher territory count/density. The dataset included 23 predictor variables (Table 2), several of which were less informative than or correlated with other predictors. Multiple regression cannot identify which predictors are associated with the response when there is collinearity (Graham 2003). Data exploration was the major part of the statistical analysis, with the goal to detect patterns in the data and simplify and reduce collinearity in the dataset 
234 (Zuur et al. 2010). This involved three steps: 1) spatial patterns (bubble maps, correlograms);

235 2) bivariate associations and interactions between predictors (scatter plots, box-and-whisker

236 plots), and; 3) collinearity (for continuous predictors).

237 A simple method for visualising collinearity among continuous predictor variables is a cluster

238 analysis using correlation coefficients. Clusters were identified by cutting the dendrogram at

239 Spearman $r^{2}=0.49$ (equivalent to $|r|<0.7$ ). Collinear variables within an identified cluster

240 were combined if this could be done using simple arithmetic (e.g. the sum of two collinear

241 count variables) else the variable with the strongest correlation with the response variable

242 was selected (Dormann et al. 2013).

243 Multiple regression was used for modelling oystercatcher counts because this method allows

244 for simple and interpretable inference and the sample size was unbalanced and effectively

245 small, with high oystercatcher densities on only a few beaches. Repeated-measures 'mixed-

246 models' were not necessary because replicate oystercatcher counts from each beach were

247 fairly precise, the number of replicate counts was as small as three and estimating the

248 variance among these repeated counts was of no interest (Murtaugh 2007).

249 Generalised linear models (GLMs) with a log link were fitted to integer oystercatcher mean

250 counts (rounded to zero decimal places) and oystercatcher territory counts. The negative

251 binomial error distribution was assumed when there was over dispersion in Poisson model

252 residuals. Beach length was included as an offset term was included in GLMs to effectively

253 model density, where:

$$
\log \left(\frac{\text { count }}{\text { length }}\right)=\cdots
$$

254 is equivalent to:

$$
\log (\text { count })=1 \times \log (\text { length })+\cdots
$$

255 and the fixed coefficient of one for $\log ($ length $)$ indicates that it is an offset.

256 With a log link, the GLM is a multiplicative model:

$$
\text { count }=\text { length } \times e^{\beta_{0}} \times e^{\beta_{1} x_{1}} \times e^{\beta_{2} x_{2}} \ldots
$$

257 where the $x_{i}$ are the predictor variables and $\beta_{i}$ are estimated coefficients. The above formula

258 predicts oystercatcher density (count/length) as some constant value $\left(e^{\beta_{0}}\right)$ multiplied by each

259 predictor term. The exponential function implies monotonic, non-linear effects which is an

260 advantage if there are such non-linear associations in the data or a disadvantage if there are

261 linear or other patterns. However, an additive, ordinary linear model for density would have

262 involved transforming the response variable to approximately satisfy statistical assumptions

263 and then would also have been non-linear and with a difficult mean-variance relationship.

264 Zuur et al. (2010) recommended to work with the original data where possible and not to

265 apply transforms. 
266

267

268

269

270

271

272

273

274

275

276

277

278

279

280

281

282

283

284

285

286

287

288

289

290

291

292

293

294

295

296

297

298

299

300

301

302

The GLM distributional assumption was checked by plotting Dunn-Smyth randomised quantile residuals (Dunn \& Smyth 1996) versus fitted values, versus individual predictors, square-root absolute residuals versus fitted values and normal-probability plots. Four realisations of the randomised residuals were plotted.

Multiple regression analysis focussed on two groups of models: 1) a pipi abundance model (Owner \& Rohweder 2003), and; 2) models based on all predictors. The pipi abundance model formed the basis for extended models in the third group. Models were compared using small sample Akaike's Information Criterion (AICc). AIC takes the model log-likelihood and adds a penalty term for the number of predictor variables to help avoid overfitting. AICc adds a further penalty when the sample size is small relative to the number of fitted parameters (Burnham et al. 2011).

Models were compared against the minimum AICc model: $\triangle \mathrm{AICc}<2$ indicates strong support; $\triangle \mathrm{AICc}=2-7$ indicates some support; $\triangle \mathrm{AICc}=7$ to 14 indicates relatively little support and $\triangle \mathrm{AICc}>14$ indicates no support (Burnham et al. 2011). Minimum AIC models were identified using an exhaustive search of all subsets of models. The resulting $\triangle \mathrm{AICc}<2$ set included models with similar predictors and the model with the fewest variables was selected. Exhaustive searching for minimum AICc models avoids unreliable stepwise variable selection methods. Nonetheless, for the reduced collinearity dataset, the estimated model coefficients and standard errors for the 'full' models (with all predictors) were found to be reliable for variable selection.

Goodness of fit was examined by plotting fitted oystercatcher densities versus observed densities and calculating the squared Pearson linear correlation statistic $\left(r^{2}\right)$. Additionally, the explained deviance statistic is reported:

$$
D^{2}=\frac{\text { Null deviance }- \text { Residual deviance }}{\text { Null deviance }}
$$

where the null deviance is the deviance of the fitted model with the intercept only and the residual deviance is the deviance that remains unexplained by the model (Guisan $\&$ Zimmerman 2000). Predictive performance (e.g. cross-validation accuracy) was not evaluated because there were few high density sites for testing.

All GIS and statistical analyses were performed using the software R version 3.5-2 (R Core Team 2018). GIS analyses used the R packages $s p$ version 1.3.1 (Pebesma \& Bivand 2005), rgdal version 1.3-6 (Bivand et al. 2018) and raster version 3.0-2 (Hijmans 2019). Spatial analyses used the R packages $n c f$ version 1.2-6 (Bjørnstad 2018) and spdep version 0.8-1 (Bivand \& Piras 2015). Clustering of collinear predictors was performed using the R package Hmisc version 4.2-0 (Harrell 2019). Negative binomial models were fitted with the MASS package in base R (Venables \& Ripley 2002). Randomized quantile residuals were computed using the R package statmod version 1.4.32 (https://CRAN.R-project.org/package=statmod). Spatial autocorrelation in GLM residuals was checked using the lm.morantest function in spdep. This function is not intended for GLMs, however no ready alternative that takes into 
303

304

305

306

307

308

309

310

311

account predictor variables was found and the results were useful for relative comparisons between models.

\section{RESULTS}

\section{Spatial patterns}

72 of 117 beaches $(62 \%)$ and 674 of $c .942 \mathrm{~km} \mathrm{(72 \% )} \mathrm{from} \mathrm{the} \mathrm{sampling} \mathrm{frame} \mathrm{were} \mathrm{sampled}$ including all of the longer beaches in NSW (except for Budgewoi on the Central Coast), all of the known pipi beaches and all beach Key Management Sites for the Australian Pied Oystercatcher (NSW DPIE 2019b) (Fig. 1). Ad hoc analysis split the coastline into five contiguous regions: SE Queensland (from Fraser Island S to the Queensland-NSW state border); Far North Coast (to Coffs Harbour); Mid-north Coast (to the Hunter River); Central Coast (to Broken Bay), Sydney (to Port Hacking), and; South Coast (to the NSW-Victoria border). Sample sizes were larger for regions where oystercatchers were more abundant: 20 of 28 beaches in the sampling frame from the Far North Coast; 27 of 30 from the Mid-north Coast, and; 18 of 37 from the South Coast. Three of 7 beaches in the sampling frame were sampled from the Central Coast (where only one oystercatcher was counted), zero of four beaches from Sydney and four of 11 beaches from SE Queensland.

A grand total of 41 Australian Pied Oystercatcher territories and 232 individual birds (the sum of mean beach counts) were counted. The majority of oystercatchers counted, 155 individuals (67\%), were non-territorial. Counts were fairly precise, with a mean range of 2.1 (i.e. \pm 1 bird). Variance increased with the mean and the maximum range was 18 for a mean count of 66 (i.e. \pm 9 birds). These fairly narrow ranges indicate that there were no substantial movements of birds in to and out of beaches between counts. Territory estimates agreed reasonably well with breeding pair counts from monitored sites (Fig. 2).

A spline correlogram (Bjørnstad \& Falck 2001) for oystercatcher mean count density indicated a spatial autocorrelation range of $63 \mathrm{~km}(95 \%$ CI 28-111 km). A radius of $50 \mathrm{~km}$ was used for calculating binary spatial weights for spatial statistics. The spatial pattern for oystercatchers was strongly aggregated with a 'hot spot' in the Richmond River area of the Far North Coast (Figs. 3a,b). Pipi abundance showed a different spatial pattern, with a hot spot in the Mid-north Coast region (Fig. 3c). Large pipis were available on all beaches and pipi mean length showed a spatial trend, increasing from an average of $c .35 \mathrm{~mm}$ on the South Coast to an average of $c .46 \mathrm{~mm}$ on the Far North Coast (Fig. 4).

\section{Bivariate associations}

A correlation matrix for all variables is presented in Table 2 and scatterplots for oystercatcher mean count density and territory count density in Figures 5 and 6 . There were positive correlations between oystercatcher count density and the proportion of the beach length protected (Spearman $r=0.47$ ) and mean pipi count (Spearman $r=0.38$ ). There were negative correlations between oystercatcher count density and the proportion of the beach length urban (Spearman $r=-0.53$ ), human population density (Spearman $r=-0.53$ ), pedestrian access density (Spearman $r=-0.45$ ), dog mean count density (Spearman $r=-0.45$ ), people mean 
342 count density (Spearman $r=-0.40$ ) and the proportion of the beach length with dogs allowed

343 (Spearman $r=-0.39$ ). Correlations were weaker than like correlations in Owner \& Rohweder

344 (2003), who sampled 11 Far North Coast beaches, $N$ of the Clarence River. This

345 disagreement was largely resolved by recomputing correlations for only Far North Coast

346 beaches in this study (Table 3). The strong oystercatcher-pipi association that was reported by

347 Owner \& Rohweder (2003) apparently holds only for the Far North Coast region (Figs. 5h,

$348 \quad 6 c)$.

349 There were 12 beaches sampled where commercial pipi fishing was observed or known from

350 other sources to occur (see Methods) and 60 beaches that were not fished. Mean pipi

351 abundance and length were 5.4 pipis/min and $5.8 \mathrm{~mm}$ greater for fished beaches than for

352 those without commercial shellfishing (Figs. 7a, b). Mean oystercatcher count density and

353 territory density were 0.36 birds $/ \mathrm{km}$ and 0.05 territories $/ \mathrm{km}$ greater on fished beaches (Figs.

$3547 \mathrm{c}, \mathrm{d})$. These results suggest that both fishers and oystercatchers target beaches with higher

355 pipi biomass. These were not equal probability samples but the sampling design selected

356 beaches where pipis and oystercatchers could be abundant, including all known fished

357 beaches. The sample of fished beaches is assumed to be exhaustive and positive bias is

358 assumed for pipi and oystercatcher abundance means for the non-fished beach sample (which

359 would act to reduce, rather than increase, observed mean differences).

360 Sixty-two beaches sampled (86\%) had transverse bar and rip inner bars and $64(89 \%)$ had

361 medium sand $(0.25-0.5 \mathrm{~mm})$. Short (2007) has previously reported that these are the most

362 common conditions for ocean beaches in NSW. With so little variation, these two variables

363 are not considered further.

\section{Collinearity}

365 Hierarchical clustering of continuous predictor variables indicated four groups of collinear

366 variables with Spearman $r^{2} \geq 0.49$ (Fig. 8). Nearly all dogs were domestic and so human and

367 dog densities were added together. The proportion of beach length protected (and where dogs

368 are not allowed) was negatively correlated with the proportion with dogs permitted

369 (Spearman $r=-0.70$ ). These two complementary variables were combined by subtracting the

370 latter from the former (which emphasises protection).

371 After eliminating two uninformative variables (see the previous section) and acting to reduce

372 collinearity, the set of predictors was reduced from 21 to 17 variables (Table 2). The same

373 predictors were adopted for oystercatcher territory density, where correlations were similar to

374 those for oystercatcher mean count density. Square-root transforms were applied to human

375 population density, people plus dogs mean count density and pedestrian access density to

376 improve model fit ( $\triangle \mathrm{AICc}>2$ for univariate oystercatcher mean count density models). The

377 square-root transform was assumed because, unlike the logarithmic transform, application is

378 straightforward for zero values. 


\section{Oystercatcher density models}

Oystercatcher density models are summarised in Table 5. The selected oystercatcher mean count density minimum AICc model was, for the Far North Coast region:

$$
\log (\text { count. } B)=\log (\text { length })+8.83+0.17 \text { pipis }-3.4 \text { prop.urban }-1.4 \mathrm{e}^{-03} \mathrm{y}
$$

and, for other regions:

$$
\log (\text { count. } B)=\log (\text { length })+7.55+0.048 \text { pipis }-3.4 \text { prop.urban }-1.4 \mathrm{e}^{-03} \mathrm{y}
$$

This model incorporates a strong, positive pipi effect for the Far North Coast relative to other regions (Fig. 5h) and a negative urban effect. The large intercept occurs because of large UTM y values (note UTM y is in km). This model suggests a negative S-N gradient even though the highest oystercatcher densities were on the Far North Coast. In combination with the other predictors, the negative $\mathrm{S}-\mathrm{N}$ gradient could be fitting the high pipi abundance, nonurban, low oystercatcher density Teewah and 75 Mile beaches in SE Queensland.

There was some support for the alternate predictors urban proportion ( $\triangle \mathrm{AICc}=4.1), \mathrm{UTM} \mathrm{x}$ $(\triangle \mathrm{AICc}=3.9)$ and an oystercatcher mean count density model without UTM y $(\triangle \mathrm{AICc}=$ 6.0). There was no support for the alternate predictor mean people and dogs count density $(\triangle \mathrm{AICc}=14.3)$ and the basic pipi abundance model $(\triangle \mathrm{AICc}=27.7)$. Fitted densities are compared with observed mean count densities in Fig. 9. The pipi abundance model $\left(r^{2}=0.53\right.$, $D^{2}=0.32$ ) provides a reasonable fit to higher densities on the Far North Coast. Including urban proportion improves the fit to lower densities $\left(r^{2}=0.55, D^{2}=0.61\right)$.

The selected oystercatcher territory density minimum AICc model was, for the Far North Coast region:

$$
\log (\text { count. } T)=\log (\text { length })-0.87+0.15 \text { pipis }-1.86 \sqrt{\text { dens. acc.people }}
$$

and, for other regions:

$$
\log (\text { count. } T)=\log (\text { length })-2.34+0.040 \text { pipis }-1.86 \sqrt{\text { dens. acc.people }}
$$

Compared to the mean count density model above, urban proportion has been replaced by pedestrian access density. There were no collinear alternative predictors for pedestrian access density (Fig. 8) and there was no support for the basic pipi abundance model ( $\triangle \mathrm{AICc}=18.2$ ). Expected zeros closely agreed with observed zeros (Table 5), which indicates that the high frequency of zeros was well described by the systematic component of the models (Warton 2005). Zero-augmented models, while conceptually appealing (Martin et al. 2005), were not necessary and the extra parameters increase AICc when these models do not substantially increase log-likelihood. Fitted densities are compared with observed territory densities in Fig. 10. For the selected model $\left(r^{2}=0.46, D^{2}=0.62\right)$ there are some false positive results (observed $=0$ and fitted $>0$ ) as well as underestimation of intermediate densities. 


\section{DISCUSSION}

Four predictors for Australian Pied Oystercatcher abundance were selected in this study: pipi abundance had a positive effect, beach front development and beach access density had negative effects and regional/spatial predictors accounted for regional/spatial variability. The first three of these predictors are habitat variables and it is proposed that the fourth results from local and regional population histories.

Some readers would be aghast at the ad hoc descriptive modelling (sensu Shmueli 2010) and 'data mining' in this study. Some would insist that only intensive ecological studies and theory are reliable for model building (like in Goss-Custard 1996). However, there currently is not the detailed ecological knowledge for oystercatchers on ocean beaches to attempt explanatory modelling. It is also not necessarily true that predictive power can be inferred from explanatory power (Smith 2000). With the usual caveat that 'association is not causation', the models in this study provide a compact summary of oystercatcher-habitat associations and indicate some potentially important variables for conservation management and further research. Predictive performance for low oystercatcher density sites is suggested to be good because negative development and human recreation effects are plausible and the correlations were clear. Predictive performance for high oystercatcher density sites is suggested to be poor because the positive pipi abundance effect varied between regions and the models do not incorporate population dynamics.

The Far North Coast supports the largest numbers of beach resident Australian Pied Oystercatchers in NSW. The NSW Wader Study Group counted 232 oystercatchers on NSW ocean beaches in Oct 1998 with 113 between the Tweed and Clarence Rivers (Owner \& Rohweder 2003). Harrison (2009) counted 26 oystercatcher territories on beaches between the Richmond River and Bonville Creek (Sawtell) in 2003 and 27 territories in 2005. There were 122 individual oystercatchers and 27 territories on the Far North Coast ( $\mathrm{N}$ of Coffs Harbour) counted in this study. Two decades of conservation management for the Australian Pied Oystercatcher in the Richmond River area and $c .200$ young fledged (NSW DPIE unpubl. data) has apparently not increased the regional population. Taylor et al. (2014) noted that high predation rates of eggs and chicks is quite normal for most oystercatcher species and then suggested that Australian Pied Oystercatcher breeding population sizes are not limited by breeding productivity.

The NSW DPIE have estimated that there are < 200 Australian Pied Oystercatcher breeding pairs in NSW (NSW DPIE 2019a), with 88 pairs at 15 Key Management Sites including 24 pairs at four beach sites: South Ballina, Broadwater, Bombing Range and a number of beaches within Yuraygir National Park (NSW DPIE 2019b). Broadwater Beach is contiguous with and was included with South Ballina Beach in this study. These data indicate that $c$. one quarter $(24 / 88=0.27)$ of oystercatcher pairs are beach residents from which it can be estimated that there are $<50(0.25 \times 200)$ beach resident pairs in NSW. This estimate and NSW Wader Study Group counts (in Owner \& Rohweder 2003) agree with 40 territories and 222 individual oystercatchers on NSW ocean beaches from this study. Exhaustive sampling of all NSW beaches would not have substantially increased these counts. 
450

451

452

453

454

455

456

457

458

459

460

461

462

463

464

465

466

467

468

469

470

471

472

473

474

475

476

477

478

479

480

481

482

483

484

485

486

487

488

489

490

The selected oystercatcher mean count density model achieved a satisfactory fit to observed densities. This model indicated that oystercatchers aggregate at Far North Coast beaches with high pipi abundance and at less urbanised beaches. The oystercatcher-pipi correlations of Owner and Rohweder (2003) were valid only for Far North Coast beaches. For example, there were several long and largely undeveloped Mid-north Coast beaches with high mean pipi counts but only moderate oystercatcher densities. Established pipi fisheries in both of these regions indicate that both have a long history of high pipi abundance and, several years after the 2003-2009 pipi crash, results from this 'snapshot' study are assumed to be representative of typical pipi abundances. The Far North Coast oystercatcher-pipi correlation in this study was defined by only two high oystercatcher density beaches: South Ballina and Bombing Range. In Owner and Rohweder (2003; who combined Ten Mile and Bombing Range beaches) this correlation was defined by only South Ballina. Exceptionally high territory densities for South Ballina and Bombing Range beaches suggest that local population histories are important and that the Far North Coast effect is not a simple predator-prey association. Despite this uncertainty about the oystercatcher-pipi relationship, mean pipi count, together with a region covariate, was useful for the ad hoc modelling of oystercatcher density in this study.

No overall negative fishing effects for pipi stocks and oystercatcher abundance were found in this study. Instead, pipi biomass and oystercatcher abundance were higher on commercially fished beaches than on unfished beaches. Together with uncertainty about the oystercatcherpipi relationship discussed above, it is recommended that the pipi harvesting threat for the Australian Pied Oystercatcher be downgraded. Objectors to this proposal are advised to conduct their own research into pipi stock dynamics and fishing effects.

Urban proportion (or human population density) substantially improved the oystercatcher mean count density model for low density beaches. The proposed explanation is that coastal development and associated human recreation disturbance displaces shorebirds from otherwise suitable habitat (reviewed by Hockin et al. 1992). For example, Harrison (2009) noted a gap in the distribution of breeding oystercatchers around the village of Patch's Beach (currently with 19 dwellings) on South Ballina Beach.

Pedestrian access density was selected for the oystercatcher territory density model. The proposed explanation is that higher access density can result in shorter separation distances between access points and shorebird habitat zones, higher intrusion rates into those zones and more frequent disturbance (Dowling \& Weston 1999; Totterman 2019c). The maximum oystercatcher territory density in this study was 0.67 pairs $/ \mathrm{km}$ for Bombing Range Beach, which is $10.5 \mathrm{~km}$ long and with zero public access. With the exception of Tallow Beach, where spot mapping indicated one territory at Tallow Creek but where breeding is not known to occur, zero oystercatcher territories were observed in this study when pedestrian access density exceeded 1.3 tracks $/ \mathrm{km}$. This result suggests that beach access points should be at least $c .800 \mathrm{~m}$ distant from oystercatcher breeding habitat.

Beach access density is not only an issue for more urban beaches. Coastal tourism can reduce the breeding range, density and breeding success for shorebirds (reviewed by Pienkowski 
491 1993). For example, Fisher et al. (1998) proposed that camping and associated pedestrian

492 traffic on the fore dunes of Fraser Island could negatively impact oystercatchers via

493 disturbance to nesting habitat. Teewah Beach and 75 Mile Beach (Fraser Island) sampled in

494 this study were long, largely undeveloped (both are within Great Sandy National Park) and

495 have high pipi abundance but also extensive beach front camping zones with high densities of

496 pedestrian and 4WD tracks. Spot mapping indicated only one oystercatcher territory (near

497 Wyuna Creek on 75 Mile Beach) for these two beaches with a combined length of $132 \mathrm{~km}$.

498 Oystercatcher counts on 75 Mile Beach appear to have declined since Fisher et al. (1998)

499 counted an average of 15 birds between Hook Point and Indian Head. The mean count in this

500 study for the same stretch of beach was three birds. This comparison suggests that vehicle-

501 based recreation conflicts with conservation objectives for Great Sandy National Park.

502 The unsatisfactory fit to observed densities for the selected oystercatcher territory density

503 model indicates that territorial birds are less responsive to habitat than are non-territorial

504 birds. For example, pipi density at South Ballina declined from $20 / \mathrm{m}^{2}$ in 2003 to near zero in

5052009 during the recent pipi crash but there remained 23 oystercatchers on the beach

506 (Totterman 2018). However, in the long term, results from this study indicate that territory

507 density decreases towards zero on beaches with higher pedestrian access density. With

508 growing development and human recreation pressures on beaches and shorebirds in SE

509 Australia (Priest, Straw \& Weston 2002), it is predicted that beach resident oystercatcher

510 populations will decline slowly as older breeders pass away and are not replaced, i.e.

511 recruitment failure despite the surplus of non-territorial birds of breeding age. It is

512 recommended that the coastal development, tourism and human recreation disturbance threats

513 for the Australian Pied Oystercatcher be upgraded.

514 Current conservation efforts for Australian Pied Oystercatchers on ocean beaches focus on

515 breeding success (Wellman et al. 2000) and will fail in the long term unless the beach habitat

516 is protected from urbanisation, tourism and intense human recreation. Recommendations

517 from this study are to focus conservation efforts on existing large beach nesting oystercatcher

518 populations and not ad hoc groups of beaches like in current Key Management Sites (a

519 number of Mid-north Coast beaches could also be recognised, in particular Stockton Beach,

520 Fraser \& Lindsey 2018), to prohibit new development for these beaches, to prohibit dogs

521 (because dogs amplify human recreation disturbance effects and non-compliance with dog

522 regulations is common, e.g. Dowling and Weston 1999) and to restrain tourism.

523 Oystercatcher breeding habitat zones need to be identified and large separation distances

524 between beach access points and these zones implemented (Totterman 2019c). 4WDs enable

525 people to access more remote sections of a beach and should be prohibited. Permits have only

526 encouraged commercialisation of beach driving, e.g. the beaches of SE Queensland and

527 Stockton and Nine Mile (Belmont) beaches in NSW.

528 The recommendations above could best be described as 'wishful thinking' because of

529 commercial interests in developing coastal land and social interests in maintaining the status

$530 q$ quo for access and recreation. Historical habitat loss to coastal development, continued poor

531 planning decisions and weak conservation management show that people have priority over

532 wildlife. Conservationists should increase pressure upon relevant public authorities to act in 
the long-term public interest, as they are required to do under relevant environmental and planning legislation, and make the 'tough decisions' to protect the remaining natural coastline.

\section{ACKNOWLEDGEMENTS}

None at this stage.

\section{REFERENCES}

Albert, C.H., N.G. Yoccoz, T.C. Edwards Jr, C.H. Graham, N.E. Zimmermann \& W. Thuiller. 2010. Sampling in ecology and evolution - bridging the gap between theory and practice. Ecography 33: 1028-1037. https://doi.org/10.1111/j.1600-0587.2010.06421.x

Australian Bureau of Statistics. 2011. Australian Population Grid 2011. Australian Government, ABS. Accessed 28 May 2017 at: https://www.abs.gov.au/ausstats/abs@.nsf/mf/1270.0.55.007

Birdlife Australia. 2018. Beach-nesting Birds. BirdLife Australia. Accessed 17 Nov 2018 at: http://www.birdlife.org.au/projects/beach-nesting-birds

Bivand, R. \& G. Piras. 2015. Comparing implementations of estimation methods for spatial econometrics. Journal of Statistical Software 63: 1-36. http://www.jstatsoft.org/v63/i18/.

Bivand, R., T. Keitt \& B. Rowlingson. 2018. rgdal: Bindings for the 'Geospatial' Data Abstraction Library. R package version 1.3-6. https:/CRAN.R-project.org/package=rgdal

Bjørnstad, O.N \& W. Falck. 2001. Nonparametric spatial covariance functions: Estimation and testing. Environmental and Ecological Statistics 8: 53-70.

Bjørnstad, O.N. 2018. ncf: Spatial Nonparametric Covariance Functions. R package version 1.2-2. https://CRAN.R-project.org/package $=$ ncf

Burnham, K.P., D.R. Anderson \& K.P. Huyvaert. 2011. AIC model selection and multimodel inference in behavioral ecology: some background, observations, and comparisons. Behavioral Ecology and Sociobiology 65: 23-35.

Dormann, C.F., J. Elith, S. Bacher, C. Buchmann, G. Carl, G. Carré, J.R. García Marquéz, B. Gruber, B. Lafourcade, P.J. Leitão, T. Münkemüller, C. McClean, P.E. Osborne, B. Reineking, B. Schröder, A.K. Skidmore, D. Zurell \& S. Lautenbach. 2013. Collinearity: a review of methods to deal with it and a simulation study evaluating their performance. Ecography 36: 27-46. doi: 10.1111/j.1600-0587.2012.07348.x

Dowling, B. \& M.A. Weston. 1999. Managing a breeding population of the Hooded Plover Thinornis rubricollis in a high-use recreational environment. Bird Conservation International 9: 255-270.

Dunn, P.K. \& G.K. Smyth. 1996. Randomized quantile residuals. Journal of Computational and Graphical Statistics 5: 236-244.

Ellers, O. 1995. Behavioral control of swash-riding in the clam Donax variabilis. The Biological Bulletin 189: 120-127. https://doi.org/10.2307/1542462 
570 Goss-Custard, J.D., A.D. West, M.G. Yates, R.W.G. Caldow, R.A. Stillman, L. 571 Bardsley, J. Castilla, M. Castro, V. Dierschke, S.E.A. Durell, G. Eichhorn, B.J. Ens, K. 572 Exo, P.U. Udayangani- Fernando, P.N. Ferns, P.A.R. Hockey, J.A. Gill, I. Johnstone, B. 573 Kalejta-Summers, J.A. Masero, F. Moreira, R.V. Nagarajan, I.P.F. Owens, C. Pacheco, 574 A. Perez-Hurtado, D. Rogers, G. Scheiffarth, H. Sitters, W.J. Sutherland, P. Triplet, 575 D.H. Worrall, Y. Zharikov, L. Zwarts \& R.A. Pettifor. 2006. Intake rates and the 576 functional response in shorebirds (Charadriiformes) eating macro-invertebrates. Biological 577 Reviews 81: 501-529.

578 Graham, M.H. 2003. Confronting multicollinearity in ecological multiple regression. 579 Ecology 84: 2809-2815.

580 Gray, C.A. 2016a. Effects of fishing and fishing closures on beach clams: experimental 581 evaluation across commercially fished and non-fished beaches before and during harvesting. 582 PLoS ONE 11: e0146122. https://doi.org/10.1371/journal.pone.0146122.

583 Gray, C.A. 2016b. Evaluation of fishery-dependent sampling strategies for monitoring a 584 small-scale beach clam fishery. Fisheries Research 177: 24-30.

Guisan, A. \& N.E. Zimmermann. 2000. Predictive habitat distribution models in ecology.

586 Ecological Modelling 135: 147-186.

587 Harrell, F.E. (with contributions from C. Dupont and many others). 2019. Hmisc: Harrell

588 Miscellaneous. R package version 4.2-0. https://CRAN.R-project.org/package=Hmisc

Harrison, A.E. 2009. The ecology of two vulnerable shorebirds (Haematopus fuliginosus and 590 H. longirostris) in sub-tropical northern NSW, Australia: implications for conservation and 591 management. PhD thesis, University of New England, Armidale, Australia.

592 Hijmans, R.J. 2019. raster: Geographic Data Analysis and Modeling. R package version 3.0593 2. https://CRAN.R-project.org/package=raster

594 Hockin, D., M. Ounsted, M. Gorman, D. Hill, V. Keller \& M.A. Barker. 1992.

595 Examination of the effects of disturbance on birds with reference to its importance in 596 ecological assessments. Journal of Environmental Management 36: 253-286.

597 Ferguson, G., D. Johnson \& H. Gorfine. 2018. Pipi Donax deltoides. In: Status of 598 Australian Fish Stocks Reports 2018 (C. Stewardson, J. Andrews, C. Ashby, M. Haddon, K. 599 Hartmann, P. Hone, P. Horvat, S. Mayfield, A. Roelofs, K. Sainsbury, T. Saunders, J. 600 Stewart, S. Nicol \& B. Wise, Eds.). Fisheries Research and Development Corporation, 601 Canberra, Australia. http://www.fish.gov.au/report/262-Pipi-2018

602 Fisher, F., M. Hockings \& R. Hobson. 1998. Recreational impacts on waders on Fraser 603 Island. Sunbird 28: 1-11.

604 Fraser, N. \& Lindsey, A. 2018. Some observations of Australian Pied Oystercatcher on 605 Worimi Conservation Lands. Whistler 12: 35-42.

606 Goss-Custard, J.D., Ed. 1996. The oystercatcher: from individuals to populations. Oxford 607 University Press, Oxford, UK. 
Johnson, D.H. 2002. The importance of replication in wildlife research. Journal of Wildlife Management 66: 919-932.

Marchant S. \& P.J. Higgins, Eds. 1993. Haematopus longirostris Pied Oystercatcher. PAges 716-726 in: Handbook of Australian, New Zealand and Antarctic birds. Vol. 2, raptors to lapwings. Oxford University Press, Melbourne, Australia.

Martin, T.G., B.A. Wintle, J.R. Rhodes, P.M. Kuhnert, S.A. Field, S.J. Low-Choy, A.J. Tyre \& H.P. Possingham. 2005. Zero tolerance ecology: improving ecological inference by modelling the source of zero observations. Ecology Letters 8: 1235-1246. doi: 10.1111/j.1461-0248.2005.00826.x

Murray-Jones, S. 1999. Conservation and management in variable environments: the surf clam, Donax deltoides. PhD thesis, University of Wollongong, Australia.

Murtaugh, P.A. 2007. Simplicity and complexity in ecological data analysis. Ecology 88: $56-62$.

NSW Department of Planning, Industry and Environment. 2019a. Threatened species. Pied Oystercatcher - profile. NSW Government, DPIE. Accessed 26 Aug 2019 at: https://www.environment.nsw.gov.au/threatenedSpecies App/profile.aspx ?id=10386

NSW Department of Planning, Industry and Environment. 2019b. Saving our species. Pied Oystercatcher (Haematopus longirostris) Key Management Sites. NSW Government, DPIE. Accessed 26 Aug 2019 at: https://www.environment.nsw.gov.au/savingourspeciesapp/project.aspx?ProfileID=10386

Owner, D. 1997. The ecology and management of the Pied Oystercatcher (Haematopus longirostris) in Northern NSW. BSc thesis, Southern Cross University, Lismore, Australia.

Owner, D. \& D.A. Rohweder. 2003. Distribution and habitat of Pied Oystercatchers (Haematopus longirostris) inhabiting beaches in northern New South Wales. Emu 103: 163170.

Pebesma, E.J. \& R.S. Bivand. 2005. Classes and methods for spatial data in R. R News 5. https://cran.r-project.org/doc/Rnews/

Pienkowski, M.W. 1993. The impact of tourism on coastal breeding waders in western and southern European overview. Wader Study Group Bulletin 68: 92-96.

Priest, B., P. Straw \& M.A. Weston. 2002. Shorebird conservation in Australia. Wingspan 12 (Supplement): 1-15.

R Core Team. 2018. R: A Language and Environment for Statistical Computing. Version 3.52. Vienna: R Foundation for Statistical Computing. http://www.R-project.org

Shmueli, G. 2010. To explain or to predict? Statistical Science 25: 289-310.

Short, A.D. 2007. Beaches of the New South Wales coast. Second Edition. Sydney University Press, Sydney, Australia.

Smith, J. 2000. Nice work — but is it science? Nature 408: 293. 
645 Totterman, S.L. 2018. Response of Australian Pied Oystercatchers Haematopus longirostris

646 to increasing abundance of the beach bivalve prey Donax deltoides. Unpubl. preprint. bioRxiv 647 444786. https://doi.org/10.1101/444786

648 Totterman, S.L. 2019a. Seasonal zonation patterns of the sandy beach bivalve Donax 649 deltoides (Bivalvia: Donacidae) in subtropical eastern Australia. Unpubl. prepint. bioRxiv 650 610576. https://doi.org/10.1101/610576

651 Totterman, S.L. 2019b. A "feet digging" swash zone sampling method for the sandy beach

652 bivalve Donax deltoides (Bivalvia: Donacidae). Unpubl. preprint. bioRxiv 686196.

653 https://doi.org/10.1101/686196

654 Totterman, S. 2019c. Distances walked by beach users and protecting shorebird habitat from 655 human recreation disturbance. Unpubl. preprint. bioRxiv 783696.

656 https://doi.org/10.1101/783696

657 Taylor, I.R. \& S.G. Taylor. 2005. Foraging behaviour of Pied Oystercatchers in the presence 658 of kleptoparasitic Pacific Gulls. Waterbirds 28: 156-161.

659 Taylor, I.R., O.M.G. Newman, P. Park, B. Hansen, C.D.T. Minton \& R. Jessop. 2014.

660 Conservation assessment of the Australian Pied Oystercatcher Haematopus longirostris.

661 International Wader Studies 20: 116-128.

662 Venables, W.N. \& B.D. Ripley. 2002. Modern Applied Statistics with S. Fourth Edition.

663 Springer, New York, USA.

664 Warton, D.I. 2005. Many zeros does not mean zero inflation: comparing the goodness-of-fit 665 of parametric models to multivariate abundance data. Environmetrics 16: 275-289.

666 Wellman L., B. Moffatt, B. Totterman \& N. Hing. 2000. A co-operative approach to 667 protecting threatened species - Pied Oystercatchers, South Ballina, Northern NSW. Pages 99668104 in: Proceedings of the NSW pest animal control conference, 25-27 Oct 2000 (S. Bulogh, 669 Ed.) . NSW Agriculture, Orange.

670 Weston, M.A., E.M. McLeod, D.T. Blumstein \& P.-J. Guay. 2012. A review of flight 671 initiation distances and their application to managing disturbance to Australian birds. Emu 672 112: 269-286.

673 Zeileis, A., C. Kleiber \& S. Jackman. 2008. Regression models for count data in R. Journal 674 of Statistical Software 27: 1-25.

675 Zuur, A.F., E.N. Ieno \& C.S. Elphick. 2010. A protocol for data exploration to avoid 676 common statistical problems. Methods in Ecology and Evolution 1: 3-14.

677 https://doi.org/10.1111/j.2041-210X.2009.00001.X 
Table 1. Table of beaches sampled in this study with oystercatcher counts (beaches are ordered $\mathrm{N}$ to $\mathrm{S}$ by mid-point latitude). Coded breeding records accompany beach territory counts: $n$ number of pairs; habitat (Beach, Estuary, Lake); observation ( $\mathrm{C}=$ Copulation; $\mathrm{N}=$ nest with eggs; $\mathrm{Y}=$ dependent young), and; $\mathrm{M}$ indicates marked nests. For example, 2BNM translates to 2 Beach Nests Marked. Several of these records were of estuary/lake resident birds and are not recorded as beach territories. Breeding pair counts data are for comparison with territory counts. Data sources are: 1) Harrison 2009 (breeding season 2005); 2) NPWS pers. comm. 2015; 3) NSW DPIE unpubl. data (br. season 2016), and; 4) NSW DPIE unpubl. data (br. season 2018), and; 5) Fraser \& Lindsey 2018 (br. seasons 2014-2017; there were only five reliable territories and probably < five breeding pairs). Nest coordinates have been used to assign breeding pairs from the NSW DPIE reports to beaches defined in this study (i.e. Broadwater Beach is included with South Ballina Beach and Black Rocks is not included with Ten Mile Beach, to the south, or Bombing Range Beach, to the north). Regions are SE Queensland (SEQ), the Far North Coast of NSW (FNC), Mid-north Coast (MNC), Central Coast (CEC) and South Coast (SOC). Bherwerre Beach is within the Commonwealth Territory of Jervis Bay. Beaches with commercial pipi fishing are indicated (Y).

\begin{tabular}{|c|c|c|c|c|c|c|c|c|c|}
\hline Beach & Region & Sampled & S-N end & $\begin{array}{l}\text { Lat. } \\
\left({ }^{\circ} \mathbf{S}\right)\end{array}$ & $\begin{array}{c}\text { Length } \\
(\mathbf{k m})\end{array}$ & $\begin{array}{l}\text { Mean } \\
\text { count }\end{array}$ & $\begin{array}{l}\text { Oystercatcher } \\
\text { Territory count }\end{array}$ & $\begin{array}{c}\text { Br. } \\
\text { pairs }\end{array}$ & Fished \\
\hline 75 Mile (Fraser Island) & SEQ & Jul-16 & $11 \mathrm{~km}$ ramp (Hook Pt.) to Indian Head & 25.33 & 84.5 & 3.3 & 1 & & \\
\hline Teewah (Cooloola) & SEQ & Jul-17 & Noosa River to Double Island Point & 26.20 & 51.0 & 7.0 & 0 & & \\
\hline Coolum & SEQ & Jul-16 & Coolum Beach to Noosa Head & 26.47 & 15.4 & 0.0 & 0 & & \\
\hline Warana & SEQ & Jul-16 & Currimundi Lake to Point Cartwright & 26.72 & 9.1 & 0.0 & 0 & & \\
\hline Kingscliff & $\mathrm{FNC}$ & Oct-18 & Cudgen Creek to Fingal Head & 28.23 & 7.0 & 0.7 & 0 & & \\
\hline Bogangar & FNC & Jul-16 & Cabarita Beach to Cudgen Creek & 28.30 & 8.6 & 0.7 & 0 & & \\
\hline Cudgera & FNC & Oct-18 & Mooball Creek to Hastings Point & 28.38 & 2.8 & 0.0 & 0 & & \\
\hline Wooyung & FNC & Jul-16 & Brunswick River to Mooball Creek & 28.46 & 16.6 & 0.7 & 0 & & \\
\hline Tallow & FNC & Oct-17 & Cocked Hat Rock to Cape Byron & 28.68 & 7.4 & 3.7 & 1 & & \\
\hline Seven Mile (Lennox Head) & FNC & Oct-17 & Lennox Head to Jews Point & 28.77 & 8.4 & 4.0 & 0 & & \\
\hline Angels \& Sharpes & FNC & Oct-18 & Black Head to Whites Head & 28.85 & 2.9 & 0.0 & 0 & & \\
\hline South Ballina & FNC & Aug-16 & Broadwater Headland to Richmond River & 28.96 & 23.0 & 66.0 & 11 & $8^{3}$ & $\mathrm{Y}$ \\
\hline Airforce & FNC & Aug-15 & Evans River to 'Coffee rocks' & 29.09 & 5.8 & 4.8 & $2(1 \mathrm{BC})$ & $2^{3}$ & \\
\hline Bombing Range & FNC & Aug-18 & Jerusalem Creek to Goanna Headland & 29.18 & 10.5 & 16.7 & 7 & $8^{4}$ & \\
\hline Ten Mile (Iluka) & FNC & Aug-16 & Shark Bay to Black Rocks & 29.31 & 12.5 & 8.7 & 1 & $1^{3}$ & $\mathrm{Y}$ \\
\hline Pippi (Yamba) & FNC & Sep-18 & Green Point to Yamba Point & 29.45 & 3.3 & 0.7 & 0 & & \\
\hline Plumbago \& Shelley (L. Arragan) & FNC & Sep-15 & Red Cliff to Shelley Beach Head & 29.55 & 4.6 & 2.7 & $1(1 \mathrm{BCM})$ & $1^{1}$ & \\
\hline Sandon & FNC & Sep-17 & Sandon River to Brooms Head & 29.64 & 7.0 & 4.3 & $2(2 \mathrm{BNM})$ & & \\
\hline Illaroo & FNC & Aug-16 & Illaroo to Sandon Bluffs & 29.72 & 9.0 & 3.3 & 0 & & \\
\hline Minnie Water Back & FNC & Sep-17 & Diggers Camp to Minnie Water & 29.79 & 2.8 & 0.7 & 0 & $0^{1}$ & \\
\hline
\end{tabular}


Wooli

Station Creek

Hearns L. \& Woolgoolga Back

\section{Moonee}

Boambee

Bonville

North Beach (Mylestom)

South Urunga (Hungry Head)

South Valla

Forster (Scotts Head)

Grassy and Middle

South Smoky

Killick

Goolawah

North Shore (Port Macquarie)

Lighthouse (Port Macquarie)

Grants (North Haven)

Dunbogan

Crowdy Bay

Crowdy Head (Harrington)

Manning Point

Old Bar

Diamond

Nine Mile (Tuncurry)

Seven Mile (Forster)

Sandbar (Smiths Lake)

Fiona \& Submarine

Mungo (Myall Lakes)

Bennetts (Hawks Nest)

One Mile (Anna Bay)

Stockton
Sep-18

MNC Sep-17

MNC Oct-16

MNC Sep-18

MNC Aug-16

MNC Sep-18

MNC Sep-15

MNC Oct-16

MNC Sep-15

MNC Aug-17

MNC Aug-16

MNC Aug-17

$\mathrm{MNC}$ Oct-16

MNC Aug-17

MNC

$\mathrm{MNC}$

$\mathrm{MNC}$

$\mathrm{MNC}$

$\mathrm{MNC}$

MNC

$\mathrm{MNC}$

$\mathrm{MNC}$

$\mathrm{MNC}$

$\mathrm{MNC}$

MNC

$\mathrm{MNC}$

$\mathrm{MNC}$

$\mathrm{MNC}$

MNC

Aug-17

Sep-15

Aug-17

Oct-16

Sep-15

Sep-18

Aug-16

Aug-17

Oct-16

Aug-17

Sep-16

Sep-17

Sep-16

Oct-15
Wooli Wooli River to Wilsons Head

Corindi River to Station Creek

Sandy Beach to Woolgoolga Headland

Moonee Creek to Look At Me Now Hd.

Boambee Creek to Corambirra Point

Bundagen Headland to Bonville Creek

Bellinger River to Bundagen Headland

Wenonah Head to Bellinger River

Nambucca Heads to Deep Creek

Scotts Head to Nambucca River

Grassy Head to Scotts Head

Korogoro Creek to Smoky Cape

Killick Creek to Hungry Hill

Racecourse Head to Crescent Head

Hastings River to Queens Head

Lake Cathie (open) to Tacking Point

Aug-16 Camden Haven Inlet to Grants Head

Diamond Head to Camden Head

Crowdy Head to Diamond Head

Harrington Inlet to Crowdy Head

Farquhar Inlet to Harrington Inlet

Wallabi Point (N) to Farquhar Inlet

Diamond Beach to Wallabi Point (S)

Wallis Lake to Hallidays Point

Booti Booti to Cape Hawke

Smiths Lake (Sandbar) to Bald Head

Yacaaba Head to Dark Point

Anna Bay

Hunter River to Birubi Point
Big Gibber Headland to Yagon Headland

29.86

29.97

30.13

30.19

30.33

30.40

30.47

30.53

30.62

30.70

30.78

30.99

31.14

31.22

31.37

31.51

31.62

31.68

31.78

31.86

31.92

31.98

32.03

32.12

32.28

32.39

32.47

32.53
6.7

3.7

2 (1BY)

$1^{2}$

0 (1EYM)

0

0

0

1

0

0

0

0

0

1

2

0

0

0

0

0

0

0

0

0

0

0

0

$1(1 \mathrm{BN})$

2 (1BC)

0

$1(1 \mathrm{BN})$

0

$\begin{array}{lll}32.77 & 2.5 & 0.0\end{array}$

$32.83 \quad 31.9 \quad 19.6$ 


\begin{tabular}{|c|c|c|c|c|c|c|c|c|}
\hline Nine Mile (Belmont) & CEC & Sep-18 & Lake Entrance to Redhead Point & 33.04 & 10.2 & 0.3 & 0 & \\
\hline Middle Camp (Cath. Hill Bay) & CEC & Sep-18 & Catherine Hill Bay & 33.15 & 1.7 & 0.0 & 0 & \\
\hline Tuggerah & CEC & Sep-16 & Tuggerah Entrance to Pelican Point & 33.31 & 7.6 & 0.0 & 0 & \\
\hline Bellambi \& Woonona & $\mathrm{SOC}$ & Oct-15 & Swimming pools to Flat Rock & 34.36 & 2.1 & 0.0 & 0 & \\
\hline Perkins (Windang) & SOC & Sep-16 & Lake Illawarra to Red Point & 34.52 & 6.6 & 0.0 & 0 & \\
\hline Seven Mile (Shoalhaven) & $\mathrm{SOC}$ & Oct-15 & Shoalhaven Hds. (open) to Crooked River & 34.81 & 12.2 & 2.0 & 0 & \\
\hline Comerong Island & $\mathrm{SOC}$ & Sep-16 & Crookhaven R. to Shoalhaven Hds. (open) & 34.88 & 4.4 & 0.7 & $0(1 \mathrm{EN}, 1 \mathrm{ENM})$ & \\
\hline Bherwerre & SOC & Sep-16 & Sussex Inlet to Cave Head & 35.17 & 6.8 & 7.6 & $2(2 \mathrm{BN})$ & $\mathrm{Y}$ \\
\hline Cudmirrah & SOC & Sep-17 & Cudmirrah to Sussex Inlet & 35.19 & 3.6 & 0.0 & 0 & \\
\hline Buckleys \& Conjola & $\mathrm{SOC}$ & Sep-16 & Narrawallee Inlet to Conjola Lake & 35.28 & 4.6 & 1.3 & 0 (1ENM, 1LNM) & \\
\hline Wairo & SOC & Sep-17 & Tabourie Creek to Lagoon Head & 35.43 & 4.7 & 1.7 & 0 & \\
\hline Durras Lake South & SOC & Sep-16 & Durras to Durras Lake (open) & 35.65 & 2.2 & 0.0 & $1(1 \mathrm{LNM})$ & \\
\hline Bengello (Moruya North) & $\mathrm{SOC}$ & Sep-16 & Moruya River to Broulee Head & 35.88 & 5.9 & 0.0 & 0 & \\
\hline Pedro \& Moruya South & SOC & Sep-17 & Congo Point to Toragy Point & 35.94 & 4.8 & 0.0 & $1(1 \mathrm{ENM})$ & \\
\hline Bingie & SOC & Oct-15 & Coila Lake (open) to Bingie Bingie Point & 36.03 & 3.8 & 0.0 & 0 & \\
\hline Brou Lake & SOC & Oct-15 & Lake Mummuga to Jemisons Point & 36.14 & 6.5 & 5.0 & 0 & \\
\hline Wallaga & SOC & Sep-16 & Wallaga Lake to Tilba Head & 36.35 & 5.1 & 2.7 & 0 & \\
\hline Baragoot & $\mathrm{SOC}$ & Sep-17 & Cuttagee Point to Baragoot Point & 36.47 & 3.1 & 1.3 & 0 & \\
\hline Gillards \& Middle & SOC & Oct-15 & Cowdroys Head to Middle Beach & 36.66 & 3.0 & 1.0 & $0(1 \mathrm{LN})$ & \\
\hline Merimbula & $\mathrm{SOC}$ & Oct-15 & Pambula Beach to Merimbula Lake & 36.92 & 5.8 & 0.7 & 0 & \\
\hline Wonboyn & $\mathrm{SOC}$ & Oct-15 & Greenglade to Bay Cliff & 37.27 & 4.1 & 1.7 & 0 & \\
\hline
\end{tabular}


Table 2. Table of variables used in the statistical analysis. Extensive variables were converted to densities (dens.) and proportions (prop.) by dividing by beach length. Final variables are those resulting from data exploration (see Results). Generalised linear models fitted oystercatcher counts (count.T, count.TNF) with a log link and beach length as an offset. Square-root transforms were applied to a few predictor variables to improve model fit. Regions are SE Queensland (SEQ), the Far North Coast of NSW (FNC), Mid-north Coast (MNC), Central Coast (CEC) and South Coast (SOC).

\begin{tabular}{|c|c|c|c|c|}
\hline \multicolumn{2}{|c|}{ Measured variables } & \multirow[b]{2}{*}{ Scale } & \multicolumn{2}{|c|}{ Final variables } \\
\hline Description & Name & & Name & Transform \\
\hline Oyc. terr. count & count.T & length & count/dens.T & \\
\hline Oyc. mean count & count.B & length & count/dens.B & $\operatorname{round}($ count. $B, 0)$ \\
\hline Beach length & length & & length & \\
\hline Urban length & length.urban & length & prop.urban & \\
\hline 4WD length & length.4WD & length & prop. $4 W D$ & \\
\hline Dogs length & length.dogs & length & & \\
\hline Dogs off-leash length & length.offleash & length & prop.offleash & \\
\hline Protected area length & length.protect & length & protect & (prop.protect-prop.dogs) \\
\hline Pedestrian access & access.people & length & dens.acc.people & $\sqrt{ }($ dens.access.people $)$ \\
\hline 4WD access & access. $4 W D$ & length & dens.acc. $4 W D$ & \\
\hline Camping \& c'van parks & count.camps & length & dens.camps & \\
\hline People mean count & count.people & length & dens.people.dogs & $\sqrt{ }($ dens.people + dens.dogs $)$ \\
\hline Dogs mean count & count.dogs & length & & \\
\hline 4WDs mean count & count. $4 W D s$ & length & dens.4WDs & \\
\hline Human pop. $\left(1 \mathrm{~km}^{2}\right)$ & popl & length & dens.pop1 & $\sqrt{ }($ dens.pop 1$)$ \\
\hline Pipi mean count & pipis & & pipis & \\
\hline Pipi mean length & pipis.length & & pipis.length & \\
\hline UTM x-coordinate & $x$ & & $x$ & $x / 1000$ \\
\hline UTM y-coordinate & $y$ & & $y$ & $y / 1000$ \\
\hline Mode morph. state & beach & & & \\
\hline Mode sand grain size & band & & & \\
\hline Commercial fishing & fished $(\mathrm{Y} / \mathrm{N})$ & & fished & \\
\hline Region & $\begin{array}{c}\text { region } \\
\text { (SEQ/FNC/MNC } \\
\text { /CEC/SOC) }\end{array}$ & & $\begin{array}{c}\text { region2 } \\
\text { (FNC/Others) }\end{array}$ & \\
\hline
\end{tabular}


Table 3. Spearman rank-based correlation matrix for all continuous predictor variables (Table 2). Correlations have been rounded to one decimal place and weak correlations (absolute value $<0.3$ ) are not presented.

\begin{tabular}{|c|c|c|c|c|c|c|c|c|c|c|c|c|c|c|c|c|c|c|}
\hline & $\begin{array}{l}m \\
\dot{\vec{\theta}} \\
\dot{\tilde{d}}\end{array}$ & 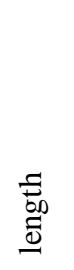 & 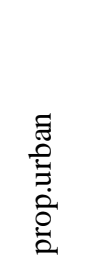 & 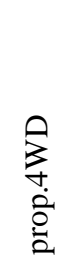 & 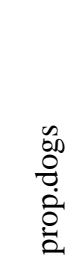 & 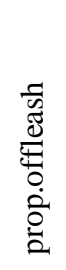 & 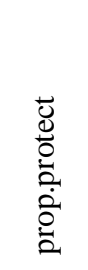 & 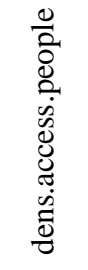 & 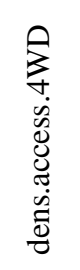 & 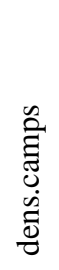 & 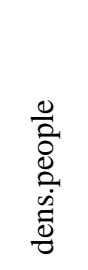 & 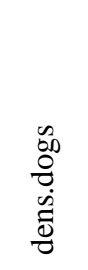 & $\begin{array}{l}\sum_{\forall} \\
\dot{\dot{0}} \\
\dot{\vec{d}}\end{array}$ & $\begin{array}{l}\vec{a} \\
0 \\
\dot{0} \\
\dot{d} \\
\vec{d}\end{array}$ & $\frac{n}{\vec{a}}$ & 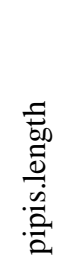 & $x$ & $\lambda$ \\
\hline dens.T & 0.6 & & & & & & 0.4 & -0.4 & & & & & & & & 0.3 & & \\
\hline dens.B & & & -0.5 & & -0.4 & & 0.5 & -0.5 & & & -0.4 & -0.5 & & -0.5 & 0.4 & & & \\
\hline length & & & & 0.5 & & & & -0.4 & 0.3 & & & & 0.3 & & 0.5 & 0.3 & & 0.3 \\
\hline prop.urban & & & & & 0.4 & 0.4 & -0.6 & 0.6 & & & 0.8 & 0.8 & & 0.8 & & & & \\
\hline prop.4WD & & & & & & & & -0.4 & 0.9 & & & & 0.8 & & 0.3 & 0.3 & & 0.3 \\
\hline prop.dogs & & & & & & 0.5 & -0.7 & 0.4 & & & 0.4 & 0.5 & & 0.5 & & & & \\
\hline prop.offleash & & & & & & & -0.6 & & & & & 0.4 & & 0.3 & & & & \\
\hline prop.protect & & & & & & & & -0.6 & & & -0.6 & -0.7 & & -0.5 & & & & \\
\hline dens.access.people & & & & & & & & & -0.3 & & 0.7 & 0.5 & & 0.6 & & & & \\
\hline dens.access.4WD & & & & & & & & & & & & & 0.8 & & 0.3 & & & \\
\hline \multicolumn{19}{|l|}{ dens.camps } \\
\hline dens.people & & & & & & & & & & & & 0.8 & & 0.7 & & & & \\
\hline dens.dogs & & & & & & & & & & & & & & 0.7 & & & & \\
\hline dens.4WD & & & & & & & & & & & & & & & 0.3 & & & \\
\hline \multicolumn{19}{|l|}{ dens.pop1 } \\
\hline \multicolumn{19}{|l|}{ pipis } \\
\hline pipis.length & & & & & & & & & & & & & & & & & 0.5 & 0.5 \\
\hline $\mathrm{x}$ & & & & & & & & & & & & & & & & & & 1.0 \\
\hline
\end{tabular}


bioRxiv preprint doi: https://doi.org/10.1101/2020.03.07 982223; this version posted March 9, 2020. The copyright holder for this preprint (which was not certified by peer review) is the author/funder, who has granted bioRxiv a license to display the preprint in perpetuity. It is made available under aCC-BY-NC-ND 4.0 International license.

Table 4. Comparison of Pearson correlation results for oystercatcher mean count density in Owner (1997; for birds/km), Owner \& Rohweder (2003; for birds $/ \mathrm{km}^{2}$ ) and results from this study (for birds/km). Far North Coast (FNC) beaches are those between Coffs Harbour and the NSW-Queensland border.

\begin{tabular}{lcccc}
\hline Oystercatcher & $\begin{array}{c}\text { Owner } \\
\text { density } ~\end{array}$ & $\begin{array}{c}\text { Owner \& } \\
\text { Rohw }\end{array}$ & $\begin{array}{c}\text { This study - } \\
\text { Rohed (2003) }\end{array}$ & $\begin{array}{c}\text { This study - } \\
\text { all beaches } \\
\text { NSW FNC }\end{array}$ \\
\hline Pipi abundance & 0.78 & 0.83 & 0.26 & $\boldsymbol{r}$ \\
Mean pipi length & 0.70 & 0.66 & 0.22 & 0.76 \\
Beach length & 0.55 & 0.64 & 0.09 & 0.72 \\
4WD count density & 0.39 & 0.24 & -0.02 & 0.04 \\
Human count density & -0.17 & -0.03 & -0.15 & -0.23 \\
\hline
\end{tabular}


Table 5. Summary of oystercatcher abundance models with small-sample Akaike's Information Criterion (AICc), explained deviance $\left(D^{2}\right)$ and squared Pearson linear correlation coefficient between observed and fitted values $\left(r^{2}\right)$. Intercept only models predict mean density for all beaches. An asterix $\left(^{*}\right)$ denotes an interaction between pipi abundance and region2 (Far North Coast/other). Size refers to the negative binomial overdispersion parameter (zero indicates a Poisson error distribution). $K$ equals the number of parameters in the model. Expected zeros can be compared with observed zeros of 25 for total oystercatcher counts and 55 for territory counts. Expected zeros is calculated from the assumed count distribution and is not the same as fitted zeros (formulae in Zeileis et al. 2008). Moran's I measures spatial autocorrelation in the residuals.

\begin{tabular}{lccccccc}
\hline Predictor variables & Size & $\boldsymbol{K}$ & $\Delta$ AICc & $\boldsymbol{D}^{\mathbf{2}}$ & $\boldsymbol{r}^{\mathbf{2}}$ & $\begin{array}{c}\text { Expected } \\
\text { zeros }\end{array}$ & $\begin{array}{c}\text { Moran's } \\
\boldsymbol{I}\end{array}$ \\
\hline Mean total count models & & & & & & & \\
pipis*region2, prop.urban, y & 0.2 & 7 & 0.0 & 0.61 & 0.55 & 25.4 & 0.03 \\
pipis*region2, prop.urban, x & 0.3 & 7 & 3.9 & 0.58 & 0.56 & 26.6 & 0.01 \\
pipis*region2, dens.pop1, y & 0.3 & 7 & 4.1 & 0.58 & 0.53 & 24.9 & 0.03 \\
pipis*region2, prop.urban & 0.4 & 6 & 6.0 & 0.54 & 0.56 & 27.6 & 0.08 \\
pipis*region2, dens.people.dogs, y & 0.3 & 7 & 14.3 & 0.51 & 0.54 & 23.5 & 0.00 \\
pipis*region2 & 0.5 & 5 & 27.7 & 0.32 & 0.53 & 25.2 & 0.09 \\
Intercept only & 1.2 & 2 & 46.7 & & 0.01 & 25.9 & 0.30 \\
Territory count models & & & & & & & \\
pipis*region2, $\sqrt{(\text { dens.acc.people) }}$ & 0 & 5 & 0.0 & 0.62 & 0.46 & 55.1 & 0.00 \\
pipis*region2 & 0.9 & 5 & 18.2 & 0.33 & 0.27 & 54.4 & 0.09 \\
Intercept only & 3.1 & 2 & 27.3 & & 0.00 & 54.8 & 0.22 \\
\hline
\end{tabular}




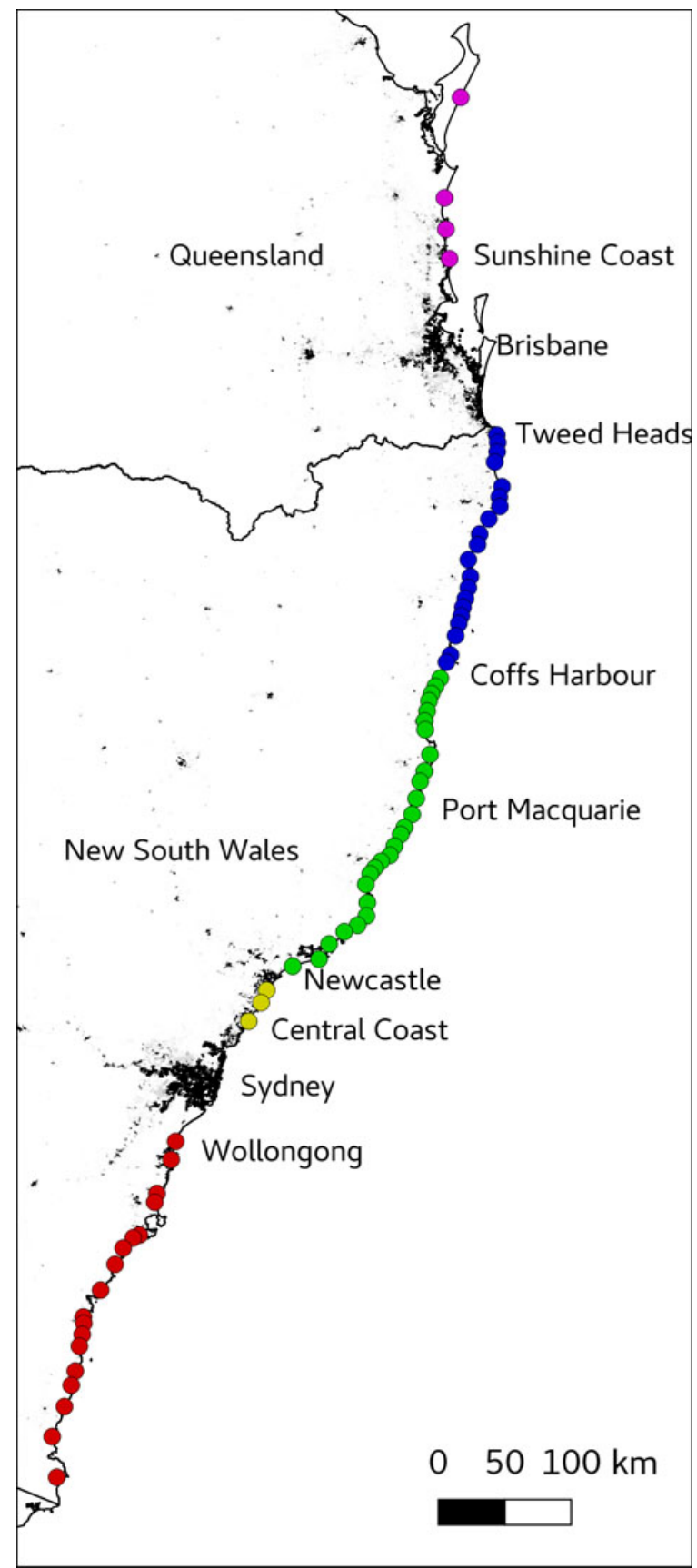

Fig. 1. Map of the SE Australian coast showing the location of beaches (circles plotted at beach centres) sampled in this study (Table 1). Colour-fill identifies regions: SE Queensland (magenta), Far North Coast (blue), Mid-north Coast (green), Central Coast (yellow) and South Coast (red). The background image shows human population densities (scale 0-1000 persons $/ \mathrm{km}^{2}$ ) from the Australian Population Grid 2011 (Australian Bureau of Statistics 2011). Text annotations identify states and larger coastal cities, towns and populated regions. 


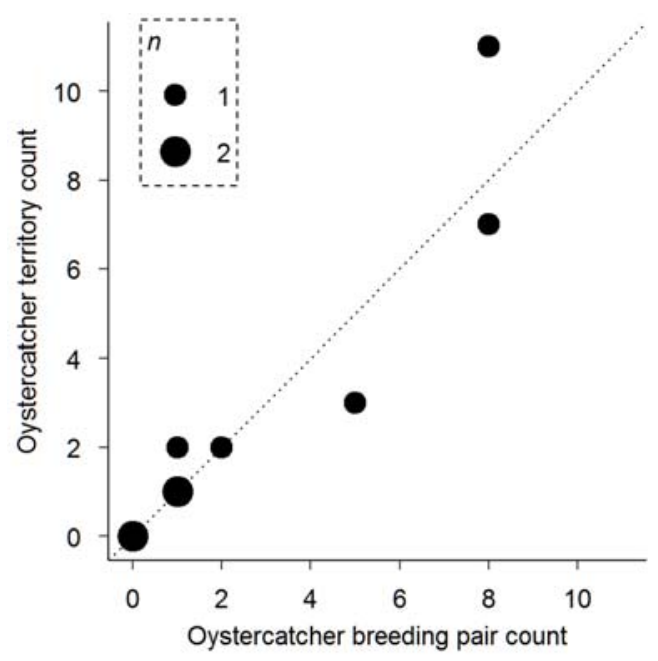

Fig. 2. Oystercatcher territory estimates from territory mapping versus breeding pairs (data and references in Table 1). Point areas are proportional to the number of observations at each location as shown in the legend. A statistical comparison is not useful because the sample size (nine beaches) is small and there is insufficient power to detect small deviations from the $1: 1$ line of agreement (dotted line). 


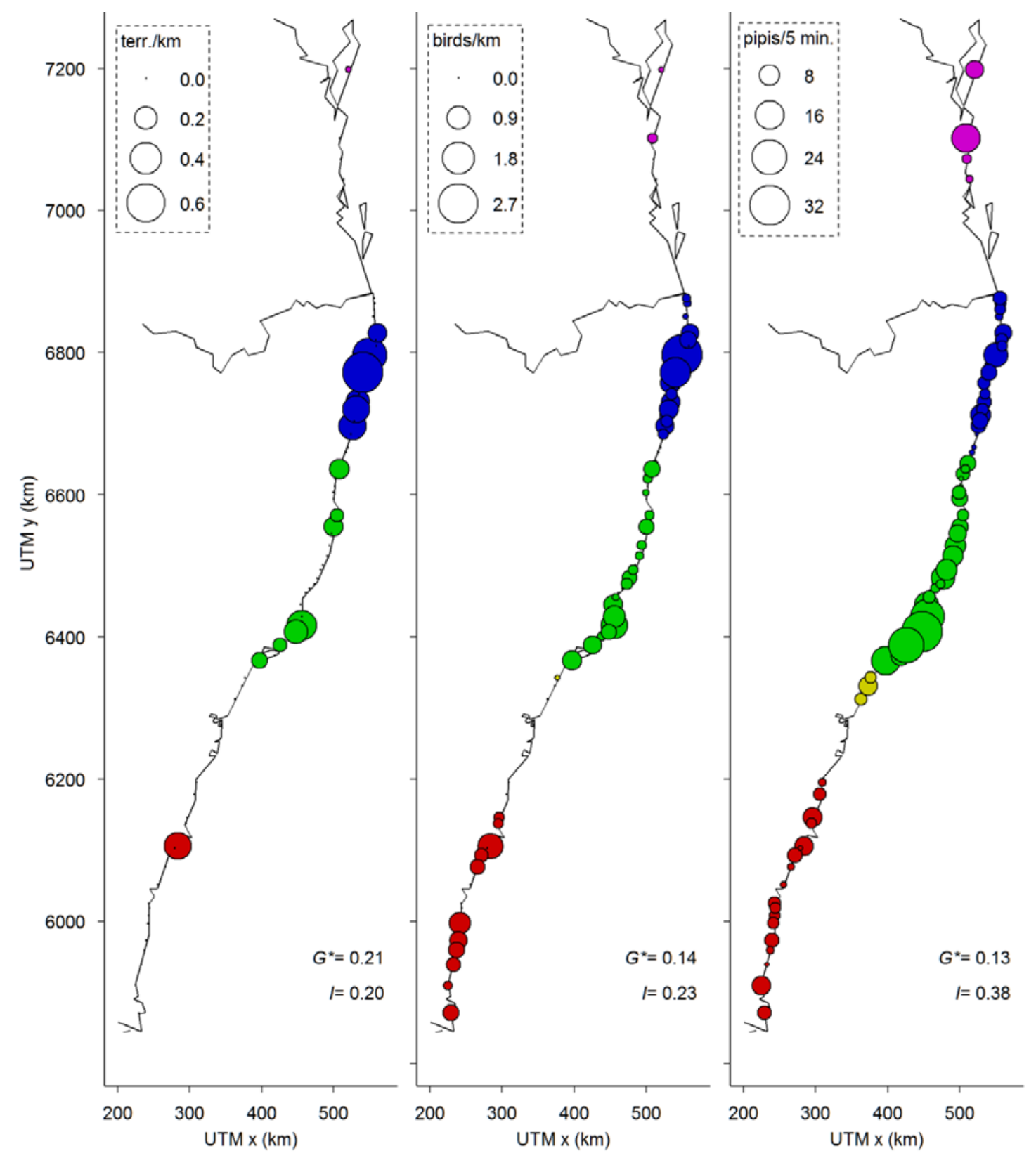

Fig. 3. Bubble maps showing spatial patterns for oystercatcher territory density (a), oystercatcher mean count density (b) and mean pipi count (c) along the SE Australian coast (Fig. 1). Circles are proportional to abundance and colour identifies regions: SE Queensland (magenta), Far North Coast (blue), Mid-north Coast (green), Central Coast (yellow) and South Coast (red). Getis-Ord $G^{*}$ and Moran's $I$ statistics measure spatial concentration and similarity (autocorrelation) respectively and all $P$-values were $<0.001$. 


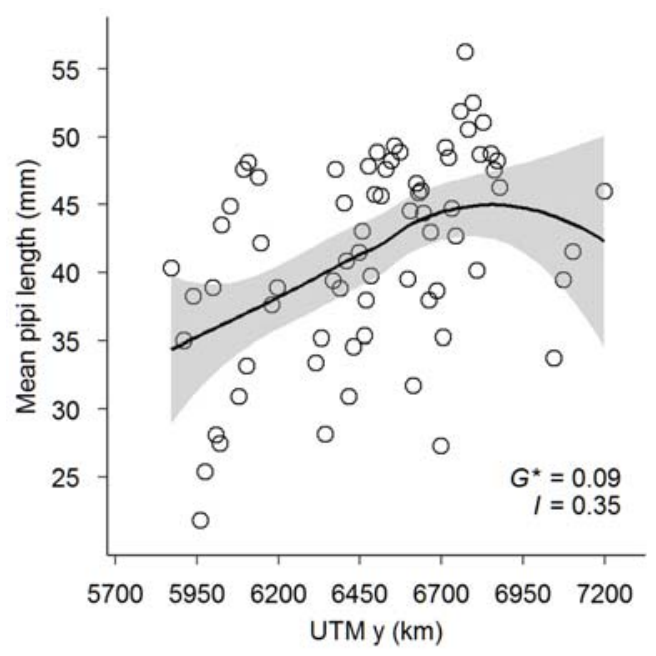

Fig. 4. Scatterplot showing the spatial trend in mean pipi length with a smooth curve fitted by local polynomial regression (the grey envelope indicates a 95\% CI). Getis-Ord $G^{*}$ and Moran's $I$ statistics measure spatial concentration and similarity (autocorrelation) respectively and all $P$-values were $<0.001$. 


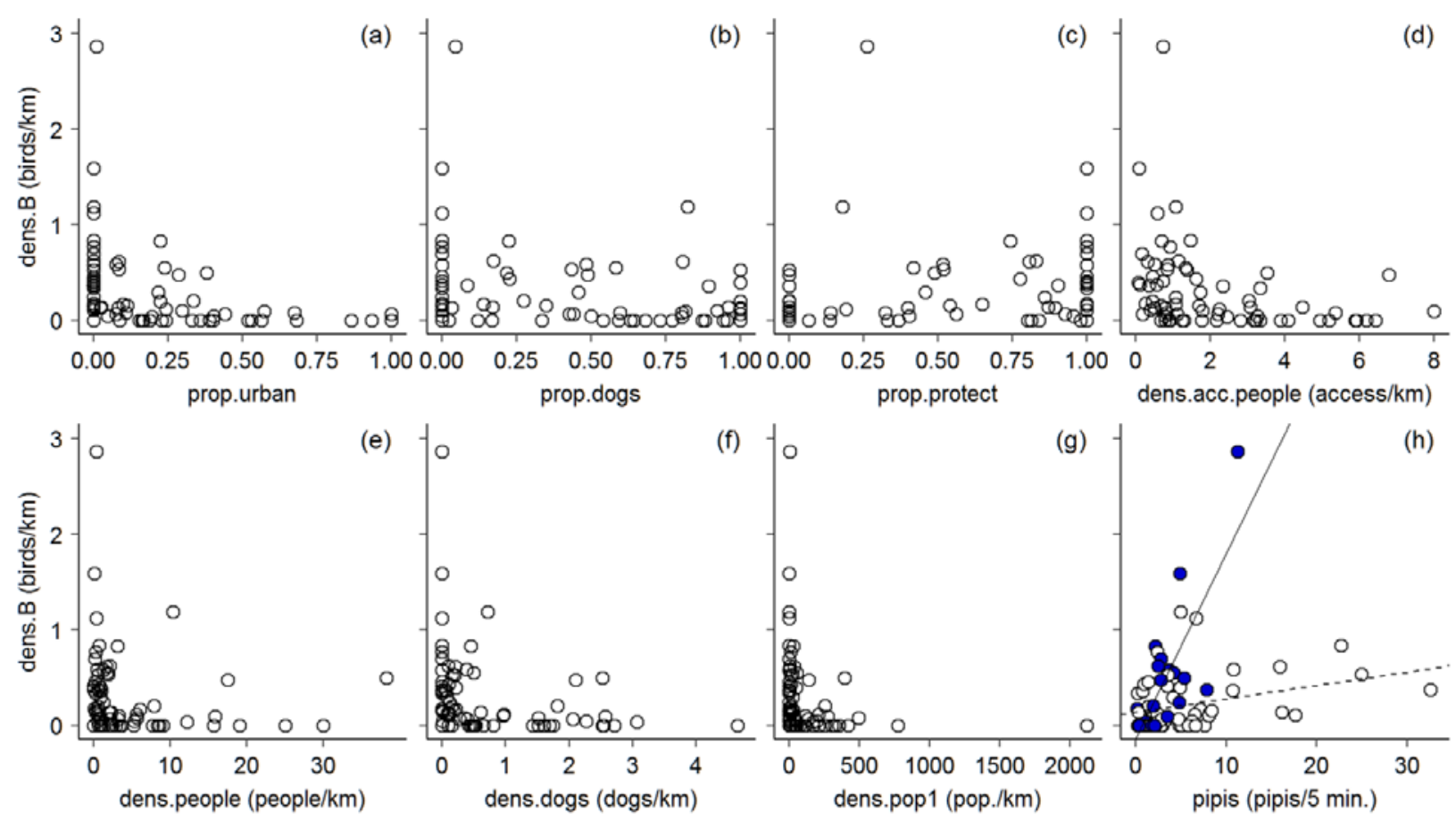

Fig. 5. Oystercatcher mean count density versus proportion of beach length urban (a), proportion of beach length with dogs allowed (b), proportion of beach length adjoining a terrestrial protected area (c), pedestrian access density (d), people mean count density (e), dogs mean count density (f), beach front human population density (g) and pipi abundance (h). All Spearman rank correlations for these scatterplots are $\geq 0.3$ (Table 3). In (h), Far North Coast beaches (Coffs Harbour to NSW-Queensland border) are plotted as blue-filled circles and other regions are plotted as white-filled circles. Oystercatcher-pipi lines were fitted by ordinary linear regression with region2 (Far North Coast/other) as a covariate.
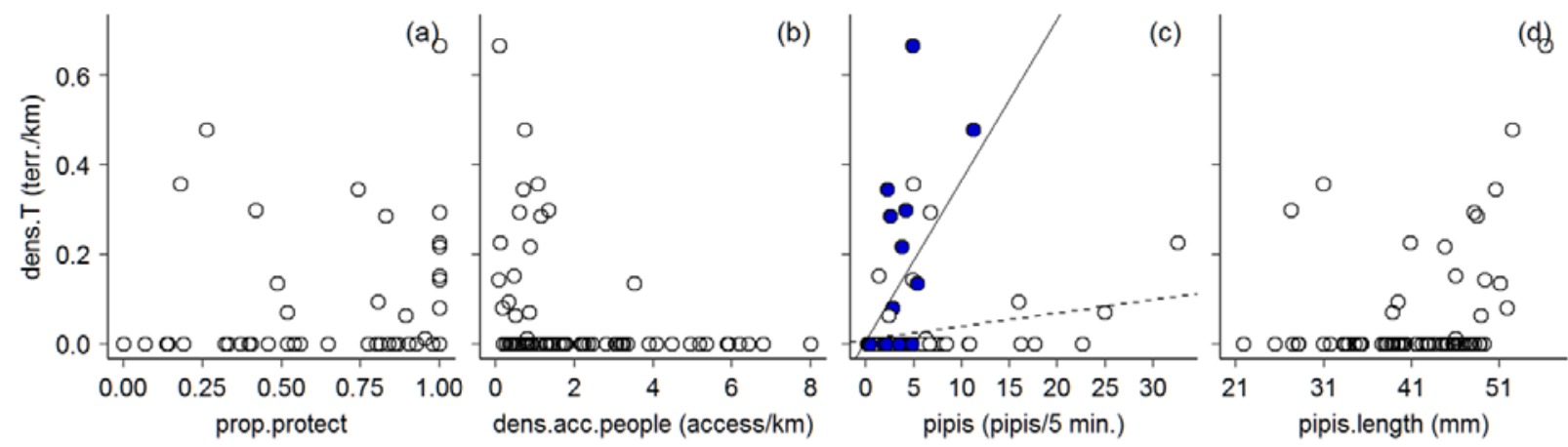

Fig. 6. Oystercatcher territory density versus proportion of beach length adjoining a terrestrial protected area (a), pedestrian access density (b), pipi abundance (c) and mean pipi length (d). All correlations for these scatterplots are $\geq 0.3$ (Table 3) except for territories-pipis (Spearman $r=0.28$ ). In (c), Far North Coast beaches (Coffs Harbour to NSWQueensland border) are plotted as blue-filled circles and other regions are plotted as white-filled circles. Territory-pipi lines were fitted by ordinary linear regression with region2 (Far North Coast/other) as a covariate. 

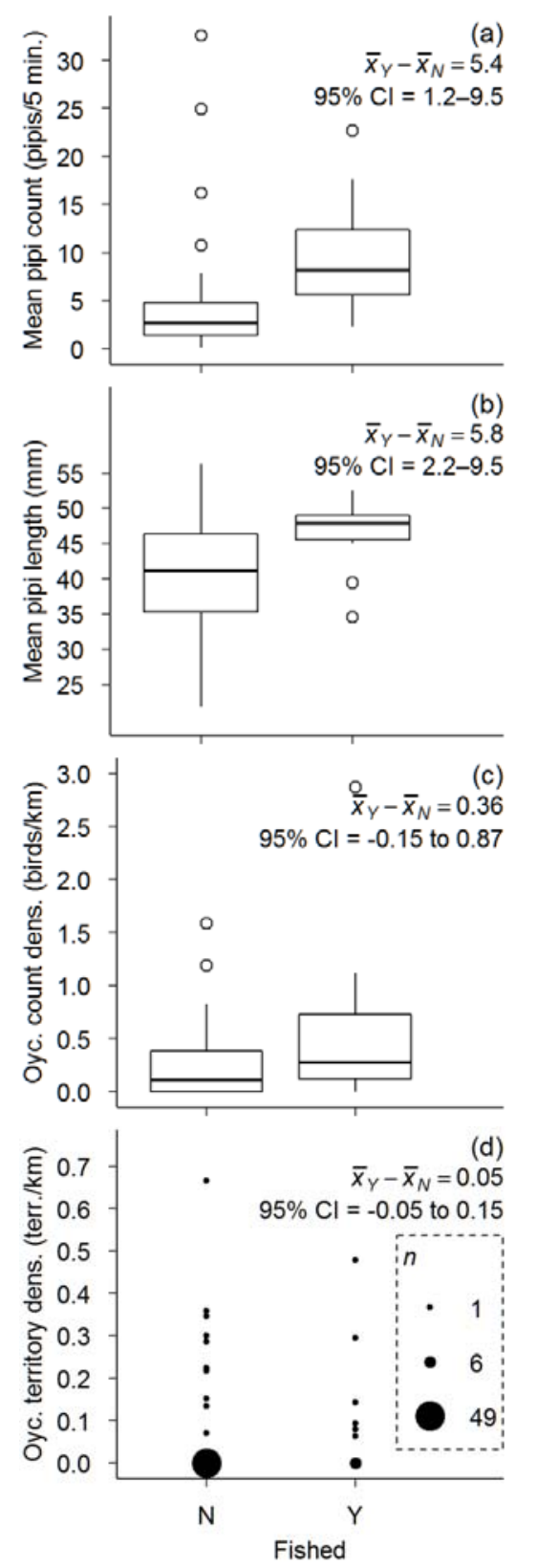

Fig. 7. Box-and-whisker plots for pipi abundance (a), pipi length (b), oystercatcher mean count density (c) and a scatterplot for oystercatcher territory density $(\mathrm{d})$, all comparing beaches with $\left(n_{Y}=12\right)$ and without $\left(n_{N}=60\right)$ commercial fishing for pipis. Boxes show the first quartile, median and third quartile, whiskers extend to a maximum of 1.5 times the interquartile range and data outside the whiskers are plotted as individual points (white-filled circles). Box-and-whisker plots were not used in (d) because of the many zeros and zero interquartile ranges. Point areas in (d) are proportional to the number of observations at each location and exactly match those in the legend. Mean difference CIs were computed using unequal variance $t$-tests with the Welch approximate degrees of freedom. 


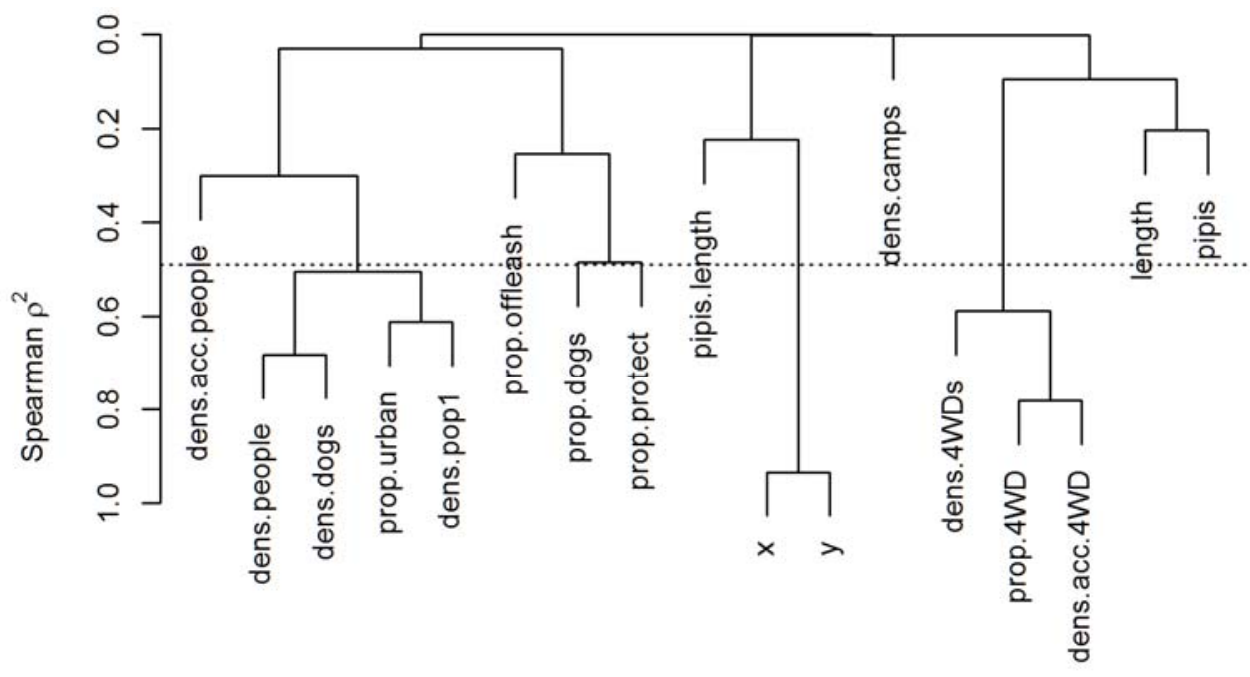

Fig. 8. Hierarchical clustering of continuous predictor variables using squared Spearman correlation coefficients. Variables are described in Table 1. The horizontal line cuts the dendrogram at Spearman $r^{2}=0.49$ and indicates four clusters of collinear variables below the line: 1) dens.people, dens.dogs, prop.urban, dens.pop 1;2) prop.dogs, prop.protect; 3) $x, y$, and; 4) dens.4WDs, prop.4WD, dens.acc.4WD. The correlation between prop.dogs and prop.protect was Spearman $r=$ -0.696 and close enough to the $r=-0.7$ cut-off. 


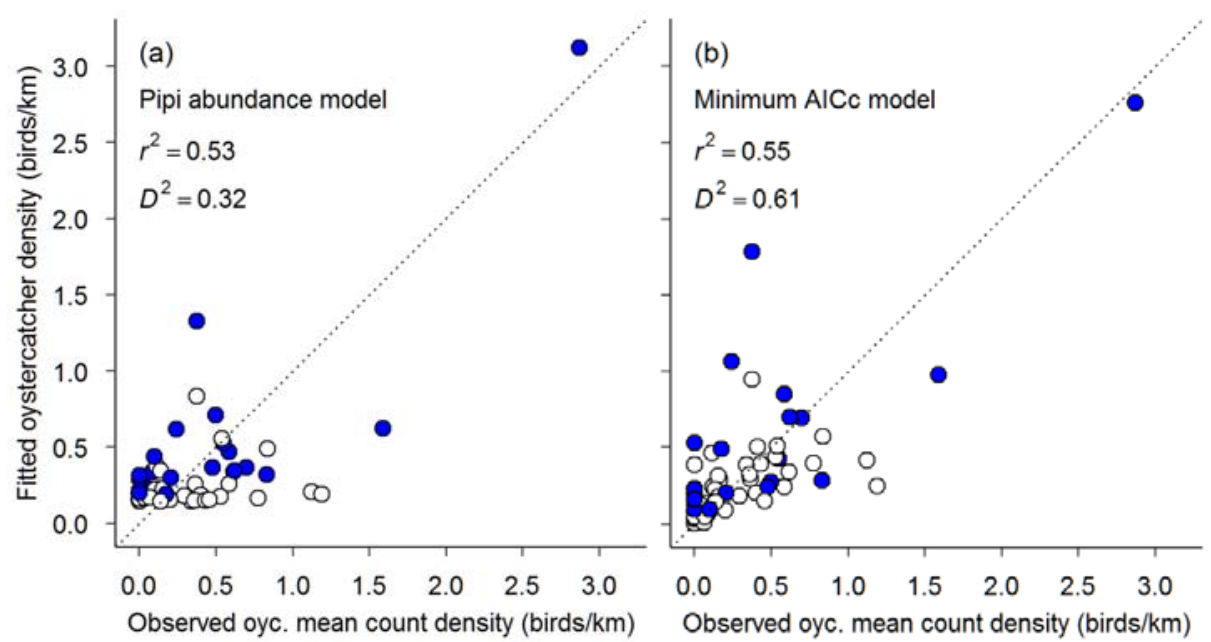

Fig. 9. Fitted versus observed oystercatcher mean count density for the pipi abundance model (a) and the selected model including urban proportion and UTM y (b). Far North Coast beaches (Coffs Harbour to NSW-Queensland border) are plotted as blue-filled circles and other regions are plotted as white-filled circles.

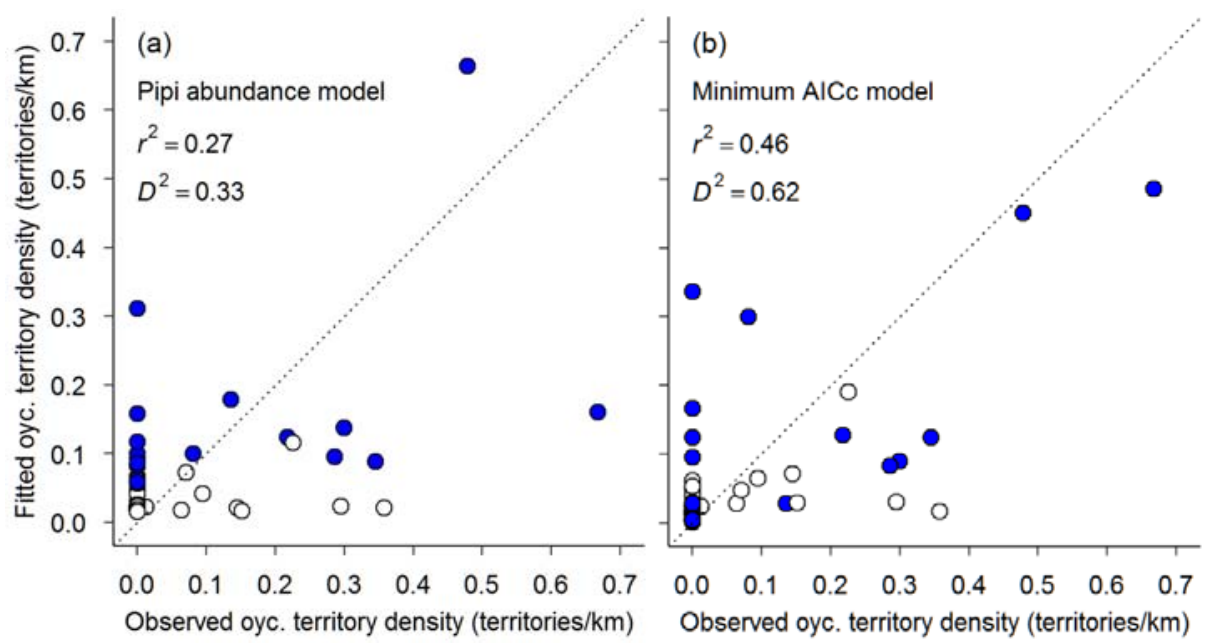

Fig. 10. Fitted versus observed oystercatcher territory density for the pipi abundance model (a) and the selected model including pedestrian access density (b). Far North Coast beaches (Coffs Harbour to NSW-Queensland border) are plotted as blue-filled circles and other regions are plotted as white-filled circles. 